Article

\title{
The Implementation of Asset Allocation Approaches: Theory and Evidence
}

\author{
Jung-Bin Su(D)
}

School of Finance, Qilu University of Technology, No.3501, Daxue Road, Changqing Dist., Jinan 250353, China; jungbinsu@gmail.com; Tel.: +86-13658628176 or +886-932201284

Received: 16 August 2020; Accepted: 31 August 2020; Published: 2 September 2020

check for updates

\begin{abstract}
This study develops three capital allocation approaches and a directional weight increment algorithm to identify the efficient frontier of all possible multi-asset portfolios precisely and rapidly. Subsequently, this study proposes an asset selection criterion, based on the coefficient of variance and volatility risk measures, to perform the asset allocation for two types of investors who are willing or not willing to bear the risk. Finally, this study uses a multivariate generalized autoregressive conditional heteroskedasticity (GARCH) model to estimate the conditional variance and covariance of several multi-asset portfolios constituted of seven assets dispersed in the oil, stock, and currency markets of the US. The empirical results show that, via applying the proposed asset selection criterion, the most suitable multi-asset portfolios are the SP500-Nasdaq and the GasNyh-DJ, which belong to the relatively most efficient portfolios. Moreover, two capital allocation approaches using the entire sample weight forecasts have the best forecast performance. Additionally, for all multi-asset portfolios the weight combination set of portfolios on the efficient frontier that resulted from the proposed algorithm is consistent with that obtained from the traditional approach.
\end{abstract}

Keywords: asset allocation; relatively most efficient portfolio; asset selection criterion; directional weight increment algorithm; capital allocation approach; generalized autoregressive conditional heteroskedasticity

\section{Introduction}

All investors want to earn a sustainable return or profit when they put capital into the financial market. In general, a high profit will be accompanied by a high risk. A high risk indicates that the price of assets will change violently. Investors with a long position hope that their assets' prices will increase upward to earn a profit, or to get a positive return. On the contrary, if their assets' prices decrease downward, then they will face a loss, or bring a negative return. In other words, investors must be concerned with both the return and risk, two important factors in the real investment process. Moreover, the risk produced by a downward price change is a bad thing for a long position. Because risk is a bad thing, the concept of diversification in modern portfolio theory (MPT) proposed by Markowitz [1] can resolve this problem. That is, a portfolio constructed of multiple assets can lower the risk. Furthermore, the greater the total number of component assets a portfolio contains, the lower the risk the portfolio bears. In reality, investors can select only a small number of assets among numerous assets in the financial market to construct their portfolio because most investors usually own limited capital, and the large number of component assets of a portfolio will be accompanied by high management cost. In a good research example of diversification in a portfolio, Tasca, Mavrodiev and Schweitzer [2] constructed a portfolio to mitigate the losses caused by the possibly excessive leverage in the financial institutions. In addition, a portfolio may be effective or ineffective depending on the capital distribution of the component assets or the weight combination of component assets, which can affect both the risk and the return of the portfolio. An effective portfolio can offer the maximum 
return for a given risk level, or bear the minimum risk for a given return. The set composed of all effective portfolios is the efficient frontier mentioned by MPT. On a two-dimensional risk-return space, a portfolio corresponding to the nose or the start point of the efficient frontier is the portfolio with minimum risk among all possible existing portfolios. The portfolio is called a minimum variance portfolio (hereafter, MVP) if the risk is measured by volatility, the square root of variance. As to the other portfolios on the efficient frontier, they lie on a right upward curve starting from the MVP, and thus the efficient frontier has a positive slope. The portfolios on the curve of the efficient frontier have the attributes of high return and high risk. According to the risk level the investors can bear, they can select the portfolios along the curve of the efficient frontier. For example, among all effective portfolios on the efficient frontier, investors who are not willing to bear the risk will select the MVP that has the minimum risk or volatility, whereas investors who are willing to bear the risk will select the portfolio with the minimum coefficient of variation $(\mathrm{CV})$, which represents the risk per unit return. It is very useful to measure all portfolios on the efficient frontier because all portfolios on the efficient frontier have the property of high risk and high return. In other words, on the efficient frontier, the return and risk of a portfolio are simultaneously higher or lower than the return and risk of another portfolio, indicating that it is difficult to compare the two portfolios on the efficient frontier via the values of return and risk by the traditional approach. Hence, if investors want to get a sustainable return they should let their portfolio be an effective portfolio, a portfolio on the efficient frontier. Because managing investments for sustainable returns is to minimize risk or maximize returns in a portfolio by staying informed about potential threats to certain industries or geographic areas [3]. Thus, 'sustainable returns' can be accomplished by the theory of efficient frontier of modern portfolio theory (MPT). Moreover, in order to get a sustainable return, Yang, Liu, Ying and Yousaf [4] and Lin, $\mathrm{Lu}, \mathrm{Su}$ and Chen [5] used the cross-sectional regression to explore which factors have the positive relation with the return or the investment behavior of investors. In other words, the above two types of investors must identify the efficient frontier precisely and rapidly to perform the asset allocation efficiently via using the $\mathrm{CV}$ and volatility risk measures. The asset allocation includes assets selection and capital allocation, the two important things the investors must do before they put the money into the financial market. Asset selection is defined as how to choose the suitable assets in the financial market. Capital allocation is how to distribute the capital into the selected assets.

Owing to the pragmatic property of MPT, it has been applied extensively in the real investment process and in empirical research on investment within recent years [2,6-13]. For instance, Tasca, Mavrodiev and Schweitzer [2] explored how to select the optimal number of projects a bank owned in order to obtain the critical diversification level via a stochastic program such as maximizing the expected utility function of the bank or minimizing the variance of bank assets. Past research studies about asset allocation [14-18] have investigated how to distribute the capital into selected assets to obtain the optimal portfolio via a stochastic program. Stochastic programs aim at "maximizing a specific utility function constraint to initial wealth balance" [14], "minimizing the square deviations of the distribution" [16], "maximizing the expected terminal wealth subtracted by the variance of terminal wealth" [17], and "maximizing the expected terminal wealth" [18]. The stochastic programs may also include "maximizing portfolio's return subtracted by the variance of portfolio's return" [19], "minimizing total factors risk" [20], "maximizing Sharpe ratio" [21], "maximizing Sortino ratio" [21], and "minimum variance of portfolio" [21-23]. For example, Aziz, Vrontos, and Hasim [21] explored, among 26 multivariate dynamic conditional correlation (DCC) generalized autoregressive conditional heteroskedasticity (GARCH) models, which model can get the best optimal portfolio for each of five different optimization strategies. The five optimization strategies are the minimum variance, mean-variance, maximizing Sharpe ratio, mean-CVaR, and maximizing Sortino ratio. The results showed that the models with the best performance are different for five optimization strategies. Cheang, Olmo, Ma, Sung and McGroarty [22] analyzed which variance forecast among three variance forecasts can get the best optimal portfolio for an optimization strategy of the minimum variance of portfolio. The three variance forecasts are historical variance, implied variance, and risk-premium-corrected 
implied variance. The results showed that risk-premium-corrected implied variance performed the best. Lv, Yang and Fang [23] explored that, as compared with the Brent and WTI crude oil futures whether the Shanghai International Energy Exchange (INE) crude oil futures can better aid investors' multi-asset allocation on the petrochemical-related stocks. They used an optimization strategy, the minimum variance of portfolio, to do multi-asset allocation. The results showed that the portfolios containing INE outperformed the other portfolios including the Brent and WTI. As compared with previous studies [14-23], they found only one effective portfolio, whereas this study obtained a set of effective portfolios, the efficient frontier. In addition, as contrasted with studies using the same optimization strategy as in this study, such as the minimum variance of portfolio [21-23], those studies focused on which model (respectively, variance forecast) among several models (respectively, variance forecasts) could get the best portfolio performance [21,22]. In contrast, Lv, Yang and Fang [23] focused on whether the INE crude oil futures could better aid investors' multi-asset allocation on petrochemical-related stocks compared to the Brent and WTI. However, this study, in investigating three weight forecast approaches, asks which weight forecast approach can get the best portfolio performance, studies how to choose the suitable assets in the financial market, and then asks how to distribute the capital to the selected assets to get a set of effective portfolios (i.e., the efficient frontier).

In order to illustrate clearly and easily the above two major tasks-how to choose the suitable assets in the financial market and how to distribute the capital into the selected assets- this study assumes that only seven assets are in the financial market and only two assets are selected to construct a portfolio. Because as reported in Caporin and McAleer [24] the problem of the "dimensional curse" will appear the BEKK-GARCH $(1,1)$ model, the empirical model of this study. This indicates that there are 21 bi-component asset portfolios because of $C_{2}^{7}=21$. The research question is which bi-component asset portfolio is the most suitable and effective portfolio. Hence, the above two major tasks can be changed: a) among the seven assets, describe how to choose the suitable two assets; and b) describe how to distribute the capital into the selected two assets. This study first uses a simple approach to explore two major tasks or two sequential steps in an investment process: assets selection and capital allocation. That is, this study uses the traditional constant weight (CW) type of capital allocation approach to find all the messages of the MVP and the weight range of component assets of all portfolios on the efficient frontier for each of $21 \mathrm{bi}$-component asset portfolios. The messages of MVP include the weight combination, return, volatility, and CV. This approach first uses the values of volatility and CV of the MVPs of 21 bi-component asset portfolios to choose the suitable effective bi-component asset portfolio because the MVP is the start point of the efficient frontier, and it carries the minimum risk among all portfolios on the efficient frontier. However, contradictory results appear in the portfolio picking process for two different types of risk measure, the volatility and CV. Then this study proposes an asset selection criterion to solve the above contradictory question to find the suitable bi-component asset portfolios for the two types of investors mentioned above. The component assets of the suitable bi-component asset portfolios are the suitable assets in the financial market. This is the step of assets selection. Notably, this asset selection criterion is a compromise method in the portfolio picking process for two types of investors who are willing or not willing to bear the risk. This is the first contribution of this study because it solves the above contradictory question. The next job is the capital allocation. According to the risk the investors are willing to take, they should distribute their capital to all component assets along the efficient frontier of this suitable component-based portfolio selected by the previous procedure of asset selection. Hence, I must identify the efficient frontier of this suitable component-based portfolio clearly. In the traditional CW approach, I can perform the capital allocation on the component assets of selected portfolios based on the weight range of component assets of all portfolios on the efficient frontier. Regarding the assets' selection process mentioned above, this study also utilizes the stochastic program of minimizing a portfolio's variance to propose three capital allocation approaches to find more quickly and more accurately the weights of component assets of an MVP as compared with the first step in the CW approach. Then, I can find all the messages of the MVP quickly and accurately. This is the second contribution of this study because the CW approach 
finds all the messages of the MVP slowly and roughly. Regarding the capital allocation, this study uses two features of the efficient frontier to propose a directional weight increment algorithm to rapidly find the weight range of component assets of all portfolios on the efficient frontier, as compared with the second step in the CW approach. This is the third contribution of this study because, to find the weight range of component assets of all portfolios on the efficient frontier, the $\mathrm{CW}$ approach mentioned above is time-consuming and not accurate. Therefore, the above proposed approaches can help investors to perform the capital allocation precisely and rapidly, and then to establish an effective portfolio for them.

Consequently, this study first utilizes a positive definite and diagonal BEKK type of bivariate GARCH model to estimate the conditional variance and covariance of $21 \mathrm{bi}$-component asset portfolios. Subsequently, for each of 21 bi-component asset portfolios, this study first uses one traditional asset allocation approach, the CW, to perform the asset allocation. However, the CW approach is time-consuming and not accurate, and thus I propose three capital allocation approaches, the CWI, DWI, and MDWI, to find quickly and precisely the weights of component assets of MVP, and to further develop a directional weight increment algorithm to rapidly find the weight range of component assets of all portfolios on the efficient frontier. The CWI, DWI, and MDWI respectively denote the constant weight for the in-sample period (CWI), dynamic weight for the in-sample period (DWI) and mean of DWI (MDWI) types of capital allocation approaches. In finding all messages of the efficient frontier for 21 bi-component asset portfolios, this study explores the following questions. First, according to all the messages of 21 MVPs gotten from the CW, how can one pick two assets among the seven assets by using two different types of risk measure? Then, I explore how to distribute the capital into the selected two assets according to the weight range of component assets of all portfolios on the efficient frontier of the selected bi-component assets portfolio. Second, which capital allocation approach has the best forecasting performance among three developed capital allocation approaches? Third, is the weight range of component assets of all portfolios on the efficient frontier from the directional weight increment algorithm consistent with that obtained from the CW approach?

Our results show that, first, regarding a single asset, the assets in the oil market incur the highest risk, followed by those in the stock market. On the other hand, the US dollar index (UDI) holds the lowest risk. Moreover, regarding a market type of portfolio, the stock market portfolios have the greatest value of positive correlation coefficient, followed by the oil market portfolios and mixed oil-stock market portfolios. In contrast, the mixed oil-FX market portfolios and mixed stock-FX market portfolios have the smallest value of correlation coefficient, and even the values of correlation coefficient are negative. Thus, the UDI is a good hedge asset, especially for assets in the oil market, because the UDI incurs the lowest risk, and the portfolios including the UDI have the smallest value of correlation coefficient and even the values of correlation coefficient are negative. Second, both the mixed oil-stock market portfolios and stock market portfolios seem to be the relatively most efficient portfolios based on the CV type of risk measure. However, based on the volatility type of risk measure, both the mixed oil-FX market portfolios and the mixed stock-FX market portfolios are the relatively minimum-variance portfolios, whereas they are the relatively most inefficient portfolios based on the CV type of risk measure, indicating that the portfolio picking process for two different types of risk measure produces contradictory results. An asset selection criterion based on the values of 'difference' and 'sum' of two different rank-order numbers respectively corresponding to the volatility and CV types of risk measure is used to solve the above question. Then, the most suitable bi-component asset portfolios are the SP500-Nasdaq $\left(w_{1} \geq w_{1}^{M V P}=1.1293\right)$ and GasNyh-DJ $\left(w_{1} \geq w_{1}^{M V P}=0.1094\right)$ which respectively belong to the stock market portfolios and the mixed oil-stock market portfolios, which are the relatively most efficient portfolios. The inequality expressions inside the bracket beside the portfolios' name denote the weigh range of first component asset of all portfolios on the efficient frontier got from both the CWI type of capital allocation approach and directional weight increment algorithm. Notably, the weight forecast of MVP obtained from the CWI is more accurate than that got from the traditional approach, the CW. Third, in taking the efficient frontier's nose obtained through the CW approach as 
the benchmark, both the MDWI and CWI, the capital allocation approaches using the entire sample weight forecasts, have the best forecast performance. On the other hand, the DWI, the capital allocation approach using the last observation sample forecast, has the worst forecast performance. Finally, regarding each of the $21 \mathrm{bi}$-component asset portfolios, the weight range of component assets of all portfolios on the efficient frontier found from the directional weight increment algorithm is consistent with that obtained from the CW approach.

The rest of this paper is organized as follows. Section 2 presents the econometric methodology, including the positive definite and diagonal BEKK type of bivariate GARCH $(1,1)$ model. Section 3 presents the theory about one traditional asset allocation approach and its improvement methods (i.e., three developed capital allocation approaches), and then provide the criteria for evaluating these approaches. Section 4 reports the data and their descriptive statistics, then illustrates the procedure of a directional weight increment algorithm, and further explores the issues of asset allocation addressed in this study. Section 5 draws some conclusions and proposes some policy implications for investors and fund managers.

\section{Econometric Methodology}

This study proposes an asset selection criterion, three capital allocation approaches and a directional weight increment algorithm to execute efficiently the asset allocation, a practical issue on the investment process. To illustrate clearly the proposed approaches, this study considers only two component assets' portfolios. Thus, for each of 21 bi-component asset portfolios, a positive definite and diagonal BEKK (Baba, Engle, Kraft, and Kroner [25]) type of bivariate GARCH(1,1) model is used to estimate the conditional variance and covariance that are used to find the portfolio variance. This model is composed of a mean equation $\left(r_{t}\right)$ and a variance-covariance equation $\left(H_{t}\right)$. The mean equation is expressed as the form of vector autoregressive with lag one (hereafter, VAR(1)) whereas the variance-covariance equation is expressed as the form of diagonal bivariate BEKK-GARCH $(1,1)$ model derived by Su [26]. Su [26] derived a positive definite type of bivariate GARCH model in diagonal representation from the BEKK model proposed by Engle and Kroner [27] by using the suggestion of Moschini and Myers [28], and he also presented the details in the Appendix of that study. This bivariate variance-covariance specification owns two properties: the positive definite in the variance-covariance matrix and the parsimony in the parameter estimation. Hence, the positive definite bivariate VAR(1)-BEKK-GARCH(1,1) model (hereafter, B-GARCH) is expressed as follows.

$$
\begin{gathered}
r_{1, t}=\phi_{10}+\phi_{11} r_{1, t-1}+\phi_{12} r_{2, t-1}+\varepsilon_{1, t}, \quad r_{2, t}=\phi_{20}+\phi_{21} r_{1, t-1}+\phi_{22} r_{2, t-1}+\varepsilon_{2, t} \\
\varepsilon_{t}=H_{t}^{1 / 2} z_{t}, \varepsilon_{t} \mid \Omega_{t-1} \sim N\left(0, H_{t}\right), \quad h_{t}=\operatorname{vech}\left(H_{t}\right)=\left[h_{11, t}, h_{12, t}, h_{22, t}\right]^{\prime} \\
h_{11, t}=\omega_{1}+\alpha_{1} \varepsilon_{1, t-1}^{2}+\beta_{1} h_{11, t-1} \\
h_{12, t}=\omega_{12}+\alpha_{12} \varepsilon_{1, t-1} \varepsilon_{2, t-1}+\beta_{12} h_{12, t-1} \\
h_{22, t}=\omega_{2}+\alpha_{2} \varepsilon_{2, t-1}^{2}+\beta_{2} h_{22, t-1} \\
\rho_{12, t}=\frac{\frac{h_{12, t}}{\sqrt{h_{11, t} \cdot h_{22, t}}}}{}
\end{gathered}
$$

where $r_{t}=\left(r_{1, t}, r_{2, t}\right)^{\prime}$ is a column vector of log returns. $r_{i, t}=\left(\ln P_{i, t}-\ln P_{i, t-1}\right) \times 100$ and $P_{i, t}$ is the close price of the $i$ th component asset at time $t$ where $i=1,2 . r_{1, t}$ (respectively, $h_{11, t}$ ) and $r_{2, t}$ (respectively, $h_{22, t}$ ) are the returns (respectively, variances) for the first and second component assets of a bi-component asset portfolio at time t, respectively. $h_{12, t}$ and $\rho_{12, t}$ respectively denote the covariance and the correlation coefficient between two abovementioned assets' returns at time t. $\varepsilon_{t}=\left(\varepsilon_{1, t}, \varepsilon_{2, t}\right)^{\prime}$ is a column vector of error terms, and its conditional distribution is assumed to follow the normal distribution with $E_{t-1}\left(\varepsilon_{t}\right)=0$ and $E_{t-1}\left(\varepsilon_{t} \varepsilon_{t}^{\prime}\right)=H_{t}$. Then $z_{t} \sim N(0, I)$ follows a bivariate Gaussian distribution with mean vector of zero $(0)$ and its variance-covariance matrix equals to the identity matrix, $I$. Moreover, $\omega_{1}=c_{11}^{2}, \alpha_{1}=a_{11,1}^{2}, \beta_{1}=g_{11,1}^{2} ; \omega_{12}=c_{12} c_{11}$, 
$\alpha_{12}=a_{11,1} a_{22,1}, \beta_{12}=g_{11,1} g_{22,1} ; \omega_{2}=c_{22}^{2}+c_{12}^{2}, \alpha_{2}=a_{22,1}^{2}+a_{22,2}^{2}, \beta_{2}=g_{22,1}^{2}+g_{22,2}^{2}$. Furthermore, $c_{11}, c_{12}$, and $c_{22}$ are the all elements of matrix $C_{0} ; a_{11,1}$ and $a_{22,1}$ (respectively, $g_{11,1}$ and $g_{22,1}$ ) are the all elements of matrix $A_{11}$ (respectively, $G_{11}$ ); and $a_{22,2}$ (respectively, $g_{22,2}$ ) is the all element of matrix $A_{12}$ (respectively, $G_{12}$ ). Additionally, the matrices $C_{0}, A_{11}, A_{12}, G_{11}$, and $G_{12}$ are the all terms of matrices expression of BEKK model proposed by Engle and Kroner [27] with $K=2, p=q=1$. Notably, this variance-covariance specification is a positive definite bivariate $\operatorname{GARCH}(1,1)$ model in diagonal representation, and hence this representation owns the following two merits. First, it owns the simple form in diagonal representation, and thus reduces the number of parameters estimated to nine. Second, it satisfies the condition of positive definite for all values of $\varepsilon_{t}$. Owing to these two merits, this model has used in the empirical researches within recent years [26,29-31]. As in the univariate case, the parameters of a bivariate GARCH model are estimated by maximum likelihood (ML) optimizing numerically the Gaussian log-likelihood function. Hence, this study expresses the log-likelihood function of positive definite type of B-GARCH model as follows.

$$
L(\psi)=\sum_{t=1}^{m} \ln \left\{f\left(r_{t} \mid \Omega_{t-1} ; \psi\right)\right\}=-\frac{m}{2} \ln 2 \pi-\frac{1}{2} \sum_{t=1}^{m}\left(\ln \left|H_{t}\right|+\varepsilon_{t}^{\prime} H_{t}^{-1} \varepsilon_{t}\right)
$$

where $\psi=\left[\phi_{10}, \phi_{11}, \phi_{12}, \phi_{20}, \phi_{21}, \phi_{22}, \omega_{1}, \alpha_{1}, \beta_{1}, \omega_{12}, \alpha_{12}, \beta_{12}, \omega_{2}, \alpha_{2}, \beta_{2}\right]$ is the vector of parameters to be estimated, $m$ denotes the sample size of estimate period, a probability density function $f(\cdot)$ is the bivariate normal density and $\Omega_{t-1}$ denotes the information set of all observed returns up to time $t-1$. $r_{t}, H_{t}$ and $\varepsilon_{t}$ are defined in Equations (1)-(3).

\section{Theory of Alternative Capital Allocation Approaches and Their Assessment Methods}

This study mainly helps two types of investors, who are willing or not willing to bear risk, to perform asset allocation efficiently. In order to illustrate clearly and easily the above task, this study assumes that only seven assets are in the financial market and selects only two assets to construct an effective portfolio. This indicates that there are 21 bi-component asset portfolios. Then, there are two practical questions that usually appear at the investment process can implement the task of asset allocation: (a) among the seven assets, how can one choose the suitable two assets? (i.e., assets selection), and (b) how can one distribute the capital into the selected two assets? (i.e., capital allocation). Moreover, the following task can solve the first question: among 21 bi-component asset portfolios, which one bi-component asset portfolio is the most suitable? Two component assets of the selected bi-component asset portfolio are the suitable two assets the investors should select. Because the MVP is a minimum risk portfolio on the efficient frontier, this study uses the values of volatility and CV on 21 MVPs to select one suitable bi-component asset portfolio among 21 bi-component asset portfolios via applying an asset selection criterion proposed in Section 4.3.1. The 21 MVPs are the portfolios corresponding to the efficient frontier's nose for 21 bi-component assets portfolios.

Regarding the above tasks or questions, this study utilizes the MPT proposed by Markowitz $[1,32]$ to tackle these problems. That is, for each of 21 bi-component asset portfolios this study utilizes the $\mathrm{CW}$ type of capital allocation approach to find all the messages of the efficient frontier that include the messages at the MVP and the weight range of component assets of all portfolios of the efficient frontier. The messages of the MVP include the weight combination, return, volatility, and CV. However, to find all the messages on the efficient frontier, the $\mathrm{CW}$ approach is time-consuming and not accurate. Thus, this study develops the CW for the in-sample period (CWI), dynamic weight for the in-sample period (DWI), and mean of DWI (MDWI) to quickly and precisely find the weights of component assets of the MVP for each of 21 bi-component asset portfolios. Moreover, based on the weights of component assets of the MVP, this study uses the features of the efficient frontier to propose a directional weight increment algorithm to find rapidly the weight range of component assets of all portfolios on the efficient frontier. Finally, taking the nose of the efficient frontier obtained through the CW approach as the benchmark, this study uses the portfolio efficiency criterion based on two 
different types of risk measure, the volatility and $\mathrm{CV}$, to assess the forecasting performance for three developed capital allocation approaches. Taking an example of the DWI approach, if the MVP from the DWI has a higher (respectively, lower) return and a lower (respectively, higher) risk than that from the CW approach, then the DWI is superior (respectively, inferior) to the CW. The above assessment method is the portfolio efficiency criteria based on volatility type of risk measure. On the other hand, if both the values of return and volatility of the MVP from the DWI are lower or higher than those from the $\mathrm{CW}$ approach, then the results of the performance comparison are uncertain. Regarding the above two cases, this study uses the CV as another risk measure. For instance, if the value of CV of the MVP obtained from the DWI is lower (respectively, higher) than that of the MVP from the CW approach, then the DWI is superior (respectively, inferior) to the CW approach because as compared with the CW approach the MVP from the DWI has a smaller (respectively, larger) risk per unit of return. Hence, the portfolio efficiency criteria based on CV risk measure can resolve the uncertainty cases above.

To illustrate the developed capital allocation approaches clearly and easily, this study uses a bi-component assets portfolio to explore the above issues.

$$
\begin{gathered}
r_{P, t}=w_{1} \cdot r_{1, t}+w_{2} \cdot r_{2, t} \\
h_{P, t}=w_{1}^{2} \cdot h_{11, t}+w_{2}^{2} \cdot h_{22, t}+2 w_{1} \cdot w_{2} \cdot h_{12, t} \\
\rho_{12, t}=h_{12, t} / \sqrt{h_{11, t} \cdot h_{22, t}}
\end{gathered}
$$

where $r_{P, t}$ and $h_{P, t}$ respectively denote the return and variance of portfolio at time $\mathrm{t} ; w_{1}$ and $w_{2}$ are the weights of the first and second component assets of a bi-component assets portfolio, respectively; $r_{1, t}, r_{2, t}, h_{11, t}, h_{22, t}, h_{12, t}$ and $\rho_{12, t}$ are defined as in Equations (1)-(3), and are estimated by B-GARCH model described in the previous section. Notably, the data series of seven assets has fourteen years, and this study uses it to perform the in-sample weight forecasts of MVP for four capital allocation approaches, the CW, CWI, DWI and MDWI. Subsequently, integrating the estimate results of B-GARCH model, this study will introduce the procedure or theory of the above-mentioned capital allocation approaches at the following subsections.

\subsection{The CW Type of Capital Allocation Approach}

In this subsection, this study introduces a traditional approach, the $\mathrm{CW}$ type of capital allocation approach. For each of 21 bi-component portfolios the CW approach is utilized to find all the messages (including the weight combination, return, volatility, and CV) of the MVP corresponding to the efficient frontier's nose and more importantly the weight range of component assets of all portfolios on the efficient frontier. This approach assumes that the weight is set at a constant for each of the two component assets during the entire in-sample period. Subsequently, the CW approach is described as follows. For each of 21 bi-component asset portfolios constituted by alternative two of seven assets mentioned above, two return series (i.e., $r_{1, t}$ and $r_{2, t}$ ) with the sample length of 3500 days or 14 years are utilized to estimate the in-sample variances and covariance of the B-GARCH model (see Equations (1)-(3)). Moreover, the values of $w_{1}$ and $w_{2}$ are assumed between -0.4 and 1.4 and obey the constraint $w_{1}+w_{2}=1$ because the short sales and leverage are allowed and the maximum ratios of short sales and leverage are set as $40 \%$. In addition, the sizes of weight increment for both w1 and $\mathrm{w} 2$ are set as 0.1 , hence there are 19 weight combinations of $\left(w_{1}, w_{2}\right)$. The 19 weight combinations of $\left(w_{1}, w_{2}\right)$ are $(-0.4,1.4),(-0.3,1.3),(-0.2,1.2),(-0.1,1.1),(0.0,1.0),(0.1,0.9),(0.2,0.8),(0.3,0.7)$, $(0.4,0.6),(0.5,0.5),(0.6,0.4),(0.7,0.3),(0.8,0.2),(0.9,0.1),(1.0,0.0),(1.1,-0.1),(1.2,-0.2),(1.3,-0.3)$, and $(1.4,-0.4)$. Thereafter, regarding a bi-component asset portfolio, the two component assets' weights (i.e., $w_{1}$ and $w_{2}$ ) and their returns (i.e., $r_{1, t}$ and $r_{2, t}$ ) are substituted into Equation (5) to get the return of bi-component asset portfolio, $r_{p, t}$. Moreover, the two component assets' weights, and their variance and covariance forecasts (i.e., $h_{11, t}, h_{22, t}$, and $h_{12, t}$ ) are substituted into Equation (6) to obtain the variance of this portfolio's return, $h_{p, t}$. At this inference process, I obtain the 19 weight-based portfolios via using the 19 weight combinations of $\left(w_{1}, w_{2}\right)$. Then, I plot these 19 weight-based portfolios on a risk-return 
space, and the collection of all such possible portfolios defines a region on this space. The left boundary of this region has the shape of a parabola, and the upper edge of this left boundary is the efficient frontier in the absence of a risk-free asset. The MVP is a portfolio just corresponding to the nose (start point) of this efficient frontier. In other words, the MVP is a weight-based portfolio that has the smallest level of volatility among the 19 weight-based portfolios for a specified bi-component asset portfolio. Once the MVP is found, then all the messages (including the weight combination, return, volatility, and CV) of the MVP are obtained. Subsequently, if the incremental (respectively, reductive) side of the MVP's weight can achieve a greater return than the MVP's return, then the weight range of component assets of all portfolios on the efficient frontier lies on the incremental (respectively, reductive) side of the MVP's weight. Hence, the above rules can find the weight range of component assets of all portfolios on the efficient frontier. Using the same inference process, I can find all the messages of the MVP and the weight range of component assets of all portfolios on the efficient frontier for the remaining 20 bi-component asset portfolios.

Subsequently, via using the values of volatility and CV on 21 MVPs, I can apply an asset selection criterion proposed in Section 4.3.1 to select one suitable bi-component assets portfolio among 21 bi-component asset portfolios for the two types of investors. Two component assets of the selected bi-component assets portfolio are the suitable two assets the investors should select. This is the work of assets selection. Then, the investors can distribute their capital into the selected two assets according to the risk they can bear based on the message of the weight range of component assets of all portfolios on the efficient frontier of the selected bi-component assets portfolio. This is the work of capital allocation.

\subsection{The DWI and MDWI Types of Capital Allocation Approach}

As described in Section 3.1, the CW approach obtains the weights of component assets of MVP for each of 21 bi-component asset portfolios not easily since it must evaluate the values of return and volatility of 19 weight-based portfolios. Thus, the CW approach is time consuming because it must evaluate the values of return and volatility for a group of weight-based portfolios especially for the small size of weight increment. Moreover, it is not accurate because the size of weight increment can affect the accuracy of this approach especially for the large size of weight increment. Notably, the smaller the size of weight increment, the more accurate the weight forecast of MVP and then the MVP forecast, but the more time consuming the calculating process. Hence, this subsection introduces the DWI and MDWI types of capital allocation approaches, the DWI and MDWI, to find the weights of component assets of MVP for each of 21 bi-component asset portfolios quickly and accurately. Regarding the DWI and MDWI approaches, the weights of the two component's assets vary with time during the in-sample period (i.e., $w_{1, t}$ and $w_{2, t}$ ), and they are determined by minimizing the portfolio's variance at any time $t$. Thus, for these two capital allocation methods, this study solves the following problem of mathematical programming to obtain the weights of two component assets of MVP for each of 21 bi-component asset portfolios.

Minimize

$$
h_{P, t}=w_{1, t}^{2} \cdot h_{11, t}+w_{2, t}^{2} \cdot h_{22, t}+2 w_{1, t} \cdot w_{2, t} \cdot h_{12, t}
$$

Subject to

$$
\sum_{i=1}^{n=2} w_{i, t}=1 \text { and }-0.4 \leq w_{i, t} \leq 1.4 \text {, for } i=1,2
$$

To find the weights of two component assets of MVP (i.e., $w_{1, t}^{M V P}$ and $w_{2, t}^{M V P}$ ), I substitute the constraint, $w_{2, t}=1-w_{1, t}$, into the $h_{P, t}$, and then perform the partial derivative of function $h_{p, t}$ with $w_{1, t}$ and solve the differential equation, $\partial h_{P, t} / \partial w_{1, t}=0$. Thus, the in-sample weight forecast series of the first component asset of MVP is equal to $w_{1, t}=\left(h_{22, t}-h_{12, t}\right) /\left(h_{11, t}+h_{22, t}-2 h_{12, t}\right)$ where $h_{11, t}, h_{22, t}$, and $h_{12, t}$ are respectively the two variance forecasts series and their covariance forecast series during the in-sample period, and they are estimated by the B-GARCH model (see, Equations (1)-(3)). Hence, for the DWI approach, the weight forecasts of two component assets of the MVP are the last observations 
of in-sample weight forecast series of the two component assets of MVP (i.e., $w_{1, m}$ and $w_{2, m}$ ) and express as follows.

$$
w_{1}^{M V P}=w_{1, m}=\frac{h_{22, m}-h_{12, m}}{h_{11, m}+h_{22, m}-2 h_{12, m}}, \text { and } w_{2}^{M V P}=w_{2, m}=1-w_{1}^{M V P}
$$

where $w_{1}^{M V P}$ and $w_{2}^{M V P}$ respectively are the first and second component assets' weights of the MVP. $\mathrm{m}$ is the sample size of in-sample period or the estimate period and it is set as 3500 in this study. $h_{11, m}$, $h_{22, m}$ and $h_{12, m}$ are respectively the last observation of the two variance forecast series and its covariance forecast series for the in-sample period. On the other hand, for the MDWI approach, the weight forecasts of two component assets of the MVP are the mean values of in-sample weight forecast series of two component assets of MVP and express as follows.

$$
w_{1}^{M V P}=\frac{1}{m} \sum_{t=1}^{m} \frac{h_{22, t}-h_{12, t}}{h_{11, t}+h_{22, t}-2 h_{12, t}} \text {, and } w_{2}^{M V P}=1-w_{1}^{M V P}
$$

where $w_{1}^{M V P}, w_{2}^{M V P}, m, h_{11, t}, h_{22, t}$, and $h_{12, t}$ are defined as above.

\subsection{The CWI Type of Capital Allocation Approach}

This subsection introduces the CWI type of capital allocation approach to find quickly and precisely the weights of component assets of MVP for each of 21 bi-component asset portfolios before the investment. Regarding this CWI approach, the weights of the two component's assets are set as a constant during the in-sample period (i.e., $w_{1}$ and $w_{2}$ ), and they are determined by minimizing the total variance of portfolio's return for the entire in-sample period. Thus, for this capital allocation method this study solves the following problem of mathematical programming to obtain the weights forecasts of two component assets of MVP.

Minimize

Subject to

$$
\sum_{t=1}^{m} h_{P, t}=\sum_{t=1}^{m}\left(w_{1}^{2} \cdot h_{11, t}+w_{2}^{2} \cdot h_{22, t}+2 w_{1} \cdot w_{2} \cdot h_{12, t}\right)
$$

$$
\sum_{i=1}^{n=2} w_{i}=1 \text { and }-0.4 \leq w_{i} \leq 1.4 \text {, for } i=1,2
$$

Regarding each term of Equation (10), I perform the summation for the entire in-sample period $(t=1, m)$, and then substitute the constraint, $w_{2}=1-w_{1}$, into them. For simplicity, I do the following settings. $a=\sum_{t=1}^{m} h_{11, t}, b=\sum_{t=1}^{m} h_{22, t}$ and $c=\sum_{t=1}^{m} h_{12, t}$. The total variance of portfolio's return for the entire in-sample period lists below.

$$
\begin{gathered}
\sum_{t=1}^{m} h_{p, t}=w_{1}^{2} \sum_{t=1}^{m} h_{11, t}+\left(1-w_{1}\right)^{2} \sum_{t=1}^{m} h_{22, t}+2 w_{1}\left(1-w_{1}\right) \sum_{t=1}^{m} h_{12, t} \\
=(a+b-2 c) w_{1}^{2}+(2 c-2 b) w_{1}+b
\end{gathered}
$$

Finally, with regard to Equation (11), this study performs the partial derivative of function $\sum_{t=1}^{m} h_{P, t}$ with $w_{1}$ and solve the differential equation, $\partial \sum_{t=1}^{m} h_{P, t} / \partial w_{1}=0$. Hence, for the CWI approach the weight forecasts of two component assets of the MVP express as follows:

$$
\begin{gathered}
w_{1}^{M V P}=\frac{b-c}{a+b-2 c}=\frac{\sum_{t=1}^{m} h_{22, t}-\sum_{t=1}^{m} h_{12, t}}{\sum_{t=1}^{m} h_{11, t}+\sum_{t=1}^{m} h_{22, t}-2 \sum_{t=1}^{m} h_{12, t}}, \text { and } w_{2}^{M V P} \\
=1-w_{1}^{M V P}
\end{gathered}
$$

where $w_{1}^{M V P}, w_{2}^{M V P}, m, h_{11, t}, h_{22, t}$, and $h_{12, t}$ are defined in Section 3.2. Notably, for the MDWI and CWI approaches, the weights of two component assets of the MVP are relative to two variance forecast series and its covariance forecast series for the entire in-sample period. Hence, this study also calls them as the capital allocation approaches using the entire sample weight forecasts. On the other hand, for the DWI approach, the weights of two component assets of the MVP only depend on the last observation 
of two variance forecast series and its covariance forecast series. This indicates that this study can call DWI as the capital allocation approach using the last observation sample weight forecast.

\section{Empirical Results}

\subsection{Data and Descriptive Statistics}

The study data comprise the daily prices of the following seven assets dispersed in the three markets of United States. The seven assets include the West Texas intermediate (WTI) crude oil (WTI; USD/barrel), Gasoline at the New York Harbor (GasNyh; USD/gallon) and Heating oil (Heating; USD/gallon) in the oil market; the S\&P500 (SP500), Dow Jones (DJ) and NASDAQ (Nasdaq) indices in the stock market; and the US Dollar Index (UDI) in the foreign exchange rate market (hereafter, FX market). The expressions inside the bracket beside the above assets denote their corresponding abbreviations. In addition, regarding the assets in the oil market, the trade units also show inside the bracket beside their abbreviations. The daily closing spot prices for the estimation period cover the period from 12 July 2001 to 7 August 2015, totaling 3500 observations. They are the trade data of the assets in the three markets of United States, and download from the Stlouisfed research website (https://fred.stlouisfed.org/). Returns define as the difference in the logarithms of two sequential daily asset prices then multiplied by 100 .

Table 1 reports the basic statistical characteristics of the seven return series for the estimation period. Regarding the average daily return, it is negative for the UDI in the FX market whereas it is positive for all assets in both the oil and stock markets, implying that the UDI and each of the others assets exhibit the opposite direction on price level. Hence, I can infer that the UDI is a good hedge asset for the assets in both the oil and stock markets. As to the others descriptive statistics, the UDI in the FX market has the smallest level of standard deviation whereas the assets in the oil market have the largest level of standard deviation, followed by those in the stock market. These results indicate that the UDI is the most conservative commodity whereas the assets in the oil market belong to the high risky commodity. Regarding the coefficient of skewness, most of return series are significantly left-skewed. As indicated by the excess kurtosis, all the values significantly exceed zero at the $1 \%$ level, thereby implying that the distribution of returns has a larger, thicker tail than the normal distribution. Moreover, all the Jarque and Bera (J-B) normality test statistics [33] are significant at the $1 \%$ level and thus reject the hypothesis of normality. From the above results, I can conclude that none of the return series is normally distributed. All the Ljung-Box $Q^{2}(20)$ statistics for the squared returns are significant at the $1 \%$ level and thus indicate that the return series exhibit linear dependence and strong ARCH effects. Hence, from the results of above preliminary data analysis, I find that a GARCH model is very suitable to capture the fat tails and time-varying volatility found in these asset return series.

Table 1. Descriptive statistics of daily return for the estimate period.

\begin{tabular}{ccccccccc}
\hline & Mean & Std. Dev. & Max. & Min. & Skewness & Kurtosis & J-B & $Q^{2}(20)$ \\
\hline WTI & 0.0137 & 2.4291 & 16.413 & -17.091 & $-0.220^{c}$ & $5.144^{c}$ & $3889.09^{c}$ & $2159.27^{c}$ \\
GasNyh & 0.0256 & 2.7237 & 23.505 & -17.889 & 0.063 & $5.076^{c}$ & $3761.55^{c}$ & $1356.97^{c}$ \\
Heating & 0.0195 & 2.2366 & 12.212 & -13.021 & $-0.153^{c}$ & $2.383^{c}$ & $842.22^{c}$ & $900.18^{c}$ \\
SP500 & 0.0161 & 1.2578 & 10.423 & -9.469 & $-0.285^{c}$ & $9.175^{c}$ & $12328.55^{c}$ & $6241.11^{c}$ \\
DJ & 0.0150 & 1.1774 & 10.325 & -8.200 & $-0.132^{c}$ & $8.778^{c}$ & $11251.80^{c}$ & $5610.73^{c}$ \\
Nasdaq & 0.0268 & 1.4421 & 9.106 & -9.587 & $-0.200^{c}$ & $4.476^{c}$ & $2946.15^{c}$ & $4811.33^{c}$ \\
UDI & -0.0048 & 0.4763 & 2.155 & -4.107 & $-0.240^{c}$ & $3.498^{c}$ & $1818.91^{c}$ & $823.93^{c}$ \\
\hline
\end{tabular}

Notes: (1) The superscript $\mathrm{c}$ at the descriptive statistics denotes that the values of that descriptive statistics are significantly at the $1 \%$ level. (2) Kurtosis denotes the excess kurtosis. (3) Jarque and Bera (J-B) statistics are based on Jarque and Bera [33], and are asymptotically chi-squared-distributed with 2 degrees of freedom. (4) $Q^{2}(20)$ statistics are asymptotically chi-squared-distributed with 20 degrees of freedom. 


\subsection{Estimation Results for a BEKK-Type Bivariate GARCH Model}

In this study, I employ the positive definite and diagonal BEKK-type bivariate VAR(1)-GARCH(1,1) model (B-GARCH) derived by Su [26] to estimate the variance and covariance of 21 bi-component asset portfolios. The 21 bi-component asset portfolios are compose of alternative two of the seven assets dispersed in the three markets of United States. According to the market type of component assets of portfolios, this study divides these 21 bi-component asset portfolios into the following five market types of portfolios. They are the three oil market portfolios, three stock market portfolios, nine mixed oil-stock market portfolios, three mixed oil-FX market portfolios, and three mixed stock-FX market portfolios. Notably, a market type of portfolio is a group of portfolio. The component assets of the above portfolio belong to some specified markets. That is, the three oil market portfolios and three stock market portfolios are composed of alternative two assets in the oil and stock markets, respectively. For example, the WTI-GasNyh, WTI-Heating, and GasNyh-Heating bi-component assets portfolios are the oil market portfolios whereas the SP500-DJ, SP500-Nasdaq, and DJ-Nasdaq bi-component assets portfolios are the stock market portfolios. The nine mixed oil-stock market portfolios are composed of one asset in the oil market and another asset in the stock market such as the WTI-SP500, WTI-DJ, WTI-Nasdaq, GasNyh-SP500, GasNyh-DJ, GasNyh-Nasdaq, Heating-SP500, Heating-DJ, and Heating-Nasdaq bi-component assets portfolios. At the same inference, the WTI-UDI, GasNyh-UDI and Heating-UDI bi-component assets portfolios are the mixed oil-FX market portfolios whereas the SP500-UDI, DJ-UDI, and Nasdaq-UDI bi-component assets portfolios are the mixed stock-FX market portfolios.

Due to the limited space, Table 2 lists the empirical results of the B-GARCH model during the estimate period only for WTI-GasNyh, WTI-SP500, WTI-UDI, GasNyh-UDI, SP500-UDI, and DJ-UDI portfolios that are from five market types of portfolios. Since the B-GARCH model is composed of a mean equation and a variance-covariance equation, hence the estimate results of these two equations can explore some properties of time series for the 21 bi-component asset portfolios. Regarding the mean equation, the parameters $\phi_{12}$ (respectively, $\phi_{21}$ ) can seize the return spillover effect from the second (respectively, first) component asset to the first (respectively, second) component asset for a specified bi-component portfolio during the estimate period. If the values of above-mentioned parameters are significantly then the return spillover effects exist between these two component assets. Regarding the variance-covariance equation, all the values of the parameters of conditional variance for the B-GARCH model $\left(\omega_{i}, \alpha_{i}\right.$ and $\beta_{i}$ for $\left.i=1,2\right)$ are significantly positive at the $1 \%$ level, implying that an $\mathrm{ARCH}$ effect and the time-varying feature of conditional variances subsist in these two component assets return series. Moreover, the values of ' $\alpha_{i}+\beta_{i}$ ' for $i=1,2$ are less than one and almost approaching 1 for each of the two component assets which constitute a portfolio, thus demonstrating that the volatility in two component assets is very persistent, and the stationary GARCH process is satisfied. Turning to the parameters of conditional covariance $\left(\omega_{12}, \alpha_{12}\right.$ and $\left.\beta_{12}\right)$, the value of $\omega_{12}$ is significantly positive for all three oil market portfolios (e.g., WTI-GasNyh) and all three stock market portfolios, indicating that a significant positive correlation exists between two assets in the same market such as the oil and stock markets. Moreover, the value of $\omega_{12}$ is significantly positive for all nine mixed oil-stock market portfolios such as WTI-SP500, implying that a significant positive correlation exists between the oil and stock markets. On the contrary, the value of $\omega_{12}$ is significantly negative only for the WTI-UDI portfolio among three mixed oil-FX and three mixed stock-FX markets, indicating that a significant negative correlation only exists in the WTI and UDI. In addition, the values of parameters $\alpha_{12}$ and $\beta_{12}$ are all significantly positive, and the values of ' $\alpha_{12}+\beta_{12}$ ' are less than one and almost approaching 1 for each paired assets, thus demonstrating that the covariance between these two component assets is very persistent and the stationary GARCH process is also satisfied. Regarding most of portfolios, the Ljung-Box $Q_{1}^{2}(20)$ and $Q_{2}^{2}(20)$ statistics for the squared returns are significant at $10 \%$ level, but they are significantly less than those of the squared returns in Table 1 . These results indicate that the phenomenon of serial correlation is reduced greatly in the standard residuals, and confirm that the BEKK-type bivariate $\operatorname{GARCH}(1,1)$ specification is sufficient for correcting the serial correlation 
of these return series in the conditional variance equation. Finally, the values of $\bar{\rho}_{12}$ in Table 2 denote the mean of conditional correlation between the two component assets in the 21 bi-component asset portfolios, and they are summarized in Table 3.

Table 2. Estimation results of bivariate-generalized autoregressive conditional heteroskedasticity (B-GARCH) model for alternative bi-component portfolios.

\begin{tabular}{|c|c|c|c|c|c|c|}
\hline & WTI-GasNyh & WTI-SP500 & WTI-Udi & GasNyh-Udi & SP500-Udi & DJ-Udi \\
\hline$\phi_{10}$ & $0.0629(0.032)^{b}$ & $0.0440(0.028)$ & $0.0551(0.028)^{a}$ & $0.0547(0.035)$ & $0.0525(0.013)^{c}$ & $0.0530(0.013)^{c}$ \\
\hline$\phi_{11}$ & $-0.0677(0.021)^{c}$ & $-0.0556(0.015)^{\mathrm{c}}$ & $-0.0456(0.015)^{\mathrm{c}}$ & $-0.0004(0.017)$ & $-0.0714(0.017)^{c}$ & $-0.0709(0.017)^{c}$ \\
\hline$\phi_{12}$ & $0.0374(0.016)^{b}$ & $0.0903(0.029)^{c}$ & $-0.0293(0.064)$ & $0.0405(0.081)$ & $-0.0302(0.031)$ & $-0.0358(0.028)$ \\
\hline$\phi_{20}$ & $0.0676(0.036)^{\mathrm{a}}$ & $0.0575(0.014)^{\mathrm{c}}$ & $-0.0072(0.006)$ & $-0.0052(0.006)$ & $-0.0030(0.005)$ & $-0.0029(0.006)$ \\
\hline$\phi_{21}$ & $-0.0463(0.023)^{\mathrm{a}}$ & $0.0008(0.007)$ & $-0.0114(0.002)^{c}$ & $-0.0083(0.002)^{c}$ & $-0.0482(0.005)^{\mathrm{c}}$ & $-0.0457(0.005)^{\mathrm{C}}$ \\
\hline$\phi_{22}$ & $0.0141(0.022)$ & $-0.0679(0.018)^{c}$ & $-0.0236(0.016)$ & $-0.0172(0.017)$ & $-0.0330(0.017)^{a}$ & $-0.0307(0.016)^{a}$ \\
\hline$\omega_{1}$ & $0.1726(0.036)^{c}$ & $0.0387(0.011)^{c}$ & $0.0505(0.016)^{c}$ & $0.0936(0.027)^{c}$ & $0.0168(0.003)^{\mathrm{c}}$ & $0.0178(0.003)^{c}$ \\
\hline$\alpha_{1}$ & $0.0981(0.012)^{c}$ & $0.0627(0.007)^{c}$ & $0.0549(0.007)^{c}$ & $0.0781(0.010)^{c}$ & $0.0806(0.009)^{\mathrm{c}}$ & $0.0923(0.009)^{\mathrm{c}}$ \\
\hline$\beta_{1}$ & $0.8736(0.015)^{c}$ & $0.9324(0.007)^{\mathrm{c}}$ & $0.9362(0.009)^{c}$ & $0.9109(0.012)^{\mathrm{c}}$ & $0.9039(0.010)^{c}$ & $0.8904(0.010)^{c}$ \\
\hline$\omega_{12}$ & $0.1051(0.021)^{c}$ & $0.0038(0.001)^{\mathrm{c}}$ & $-0.0006(4 \mathrm{e}-4)^{\mathrm{a}}$ & $-0.0006(4 \mathrm{e}-4)$ & $-7 e-6(2 e-4)$ & $-2 \mathrm{e}-5(2 \mathrm{e}-4)$ \\
\hline$\alpha_{12}$ & $0.0834(0.009)^{c}$ & $0.0420(0.004)^{c}$ & $0.0154(0.003)^{c}$ & $0.0123(0.003)^{c}$ & $0.0316(0.005)^{c}$ & $0.0361(0.005)^{\mathrm{c}}$ \\
\hline$\beta_{12}$ & $0.8923(0.011)^{c}$ & $0.9488(0.005)^{\mathrm{c}}$ & $0.9812(0.003)^{c}$ & $0.9838(0.004)^{c}$ & $0.9597(0.005)^{c}$ & $0.9548(0.005)^{c}$ \\
\hline$\omega_{2}$ & $0.1574(0.029)^{\mathrm{c}}$ & $0.0168(0.002)^{c}$ & $0.0008(0.000)^{\mathrm{c}}$ & $0.0008(0.000)^{c}$ & $0.0006(2 \mathrm{e}-4)^{\mathrm{c}}$ & $0.0006(2 \mathrm{e}-4)^{\mathrm{c}}$ \\
\hline$\alpha_{2}$ & $0.0975(0.010)^{c}$ & $0.0844(0.008)^{c}$ & $0.0386(0.004)^{c}$ & $0.0395(0.004)^{c}$ & $0.0376(0.004)^{c}$ & $0.0377(0.004)^{\mathrm{c}}$ \\
\hline$\beta_{2}$ & $0.8836(0.010)^{c}$ & $0.9015(0.009)^{\mathrm{c}}$ & $0.9583(0.004)^{c}$ & $0.9572(0.004)^{c}$ & $0.9597(0.004)^{c}$ & $0.9598(0.004)^{c}$ \\
\hline$Q_{1}^{2}(20)$ & 58.654 & 67.752 & 71.426 & 52.319 & 79.090 & 80.036 \\
\hline$Q_{2}^{\frac{1}{2}}(20)$ & $37.405^{\mathrm{b}}$ & 76.205 & $34.742^{b}$ & $34.345^{b}$ & $36.174^{b}$ & $35.546^{\mathrm{a}}$ \\
\hline LL & -14639.59 & -12296.77 & -9494.05 & -10127.67 & -6791.56 & -6606.62 \\
\hline $\bar{\rho}_{12}$ & $0.6666(0.138)$ & $0.1883(0.248)$ & $-0.2574(0.172)$ & $-0.1669(0.122)$ & $-0.0827(0.244)$ & $-0.0720(0.256)$ \\
\hline
\end{tabular}

Note: (1) The superscripts $a, b$ and $c$ at the parameter's estimates denote that the values of parameter's estimate are significant at the $10 \%, 5 \%$ and $1 \%$ levels, respectively. (2) Numbers in the parentheses are the standard errors. (3) LL indicates the log-likelihood value. (4) $Q_{1}{ }^{2}(20)$ and $Q_{2}{ }^{2}(20)$ respectively denote the Ljung-Box $Q$ test of first and second component asset of portfolio for 20th order serial correlation of the squared returns. (5) $\bar{\rho}_{12}$ denotes the mean value of conditional correlation between two component assets of a portfolio for the in-sample or estimate period.

Table 3 reports the mean value of conditional correlation between the two component assets in the 21 bi-component asset portfolios for the estimation period. As reported in the lower triangular elements of Table 3, I can observe that the three stock market portfolios $(0.8638 \sim 0.9687)$ have the greatest value of positive correlation, followed by the three oil market portfolios (0.6666 0.7813) and nine mixed oil-stock markets portfolios (0.1304 0.1883). Conversely, the three mixed oil-FX market portfolios $(-0.2574 \sim-0.1669)$ and three mixed stock-FX market portfolios $(-0.0827 \sim-0.0647)$ have the smallest value of correlation, and further these values of correlation are negative. The numbers in the bracket beside a specific market type of portfolios denote the correlation range for that market type of portfolios. For example, the values of correlation are between 0.8638 (SP500-Nasdaq) and 0.9687 (SP500-DJ) for three stock market portfolios whereas those are between 0.6666 (WTI-GasNyh) and 0.7813 (WTI-Heating) for three oil market portfolios. Hence, the portfolios including the UDI have the smallest and even negative value of correlation, thus according to portfolio theory that are described in Equation (6), I can infer that a portfolio including the UDI will have a lower risk. 
Table 3. The mean value and standard deviation of conditional correlation between the pair-wise assets for the estimate period.

\begin{tabular}{cccccccc}
\hline & WTI & GasNyh & Heating & SP500 & DJ & Nasdaq & UDI \\
\hline WTI & 1 & & & & & & \\
GasNyh & $\mathbf{0 . 6 6 6 6 ( \mathbf { 0 . 1 3 8 } )}$ & 1 & & & & & \\
Heating & $\mathbf{0 . 7 8 1 3 ( \mathbf { 0 . 1 2 4 } )}$ & $\mathbf{0 . 7 1 6 6 ( \mathbf { 0 . 1 1 6 } )}$ & 1 & & & & \\
SP500 & $0.1883(0.248)$ & $0.1528(0.205)$ & $0.1783(0.259)$ & 1 & & \\
DJ & $0.1565(0.254)$ & $0.1746(0.275)$ & $0.1464(0.264)$ & $0.9687(0.012)$ & 1 & 1 & \\
Nasdaq & $0.1557(0.251)$ & $0.1304(0.208)$ & $0.1555(0.259)$ & $0.8638(0.057)$ & $0.8761(0.046)$ & 1 \\
UDI & $-0.2574(0.172)$ & $-0.1669(0.122)$ & $-0.2078(0.157)$ & $-0.0827(0.244)$ & $-0.0720(0.256)$ & $-0.0647(0.225)$ & 1 \\
\hline
\end{tabular}

Note: (1) Numbers in the lower triangular element denote the mean value of conditional correlation between two component assets of a portfolio for the in-sample period, and they are summarized from row $\bar{\rho}_{12}$ in Table 2. (2) Numbers in parentheses are the standard errors of the above conditional correlations. (3) Bold (respectively, italic) font denotes the conditional correlation between two component assets for the Oil (respectively, Stock) market portfolios. Standard (respectively, shade) font denotes the conditional correlation between two component assets for Mixed oil-stock (respectively, Mixed oil-FX and Mixed stock-FX) market portfolios.

\subsection{The Application of a Traditional Asset Allocation Approach and Its Improvement Method}

In this subsection, this study uses a traditional CW approach and its improvement method: three capital allocation approaches, the CWI, DWI and MDWI, and a directional weight increment algorithm to explore the following three main issues. For example, Section 4.3.1 explores two practical tasks or two sequential steps in an investment process: (a) among the seven assets, how can one choose the suitable two assets? (i.e., assets selection), and (b) how can one distribute the capital into the selected two assets? (i.e., capital allocation). Section 4.3.2 investigates which capital allocation approach has the best forecasting performance among three developed capital allocation approaches. Section 4.3.3 examines is the weight range of component assets of all portfolios on efficient frontier got from the directional weight increment algorithm consistent with that obtained from the $\mathrm{CW}$ approach.

\subsubsection{An Example of Asset Allocation via a Traditional Approach}

In this paragraph, for each of 21 bi-component asset portfolios this study illustrates that how to use the CW approach to find all the messages of MVP and the weight range of component assets of all portfolios on the efficient frontier. Taking an example of WTI-Gasnyh bi-component assets portfolio, I can obtain the mean values of the return and volatility of 19 weight-based portfolios during the estimate period by using the evaluation process listed in Section 3.1. Then, I list the above data in column WTI-GasNyh of Table 4. 
Table 4. The messages of 19 weight-based portfolios for three oil market portfolios.

\begin{tabular}{|c|c|c|c|c|c|c|}
\hline$\left(w_{1}, w_{2}\right)$ & $r_{p}$ & $\sqrt{h_{p}}$ & $r_{p}$ & $\sqrt{h_{p}}$ & $r_{p}$ & $\sqrt{h_{p}}$ \\
\hline & \multicolumn{2}{|c|}{ WTI-GasNyh } & \multicolumn{2}{|c|}{ WTI-Heating } & \multicolumn{2}{|c|}{ GasNyh-Heating } \\
\hline$(-0.4,1.4)$ & 5.248 & 3.3393 & 2.8909 & 2.0650 & 2.0799 & 2.4391 \\
\hline$(-0.3,1.3)$ & 5.0454 & 3.1423 & 2.8565 & 2.0182 & 2.2483 & 2.2703 \\
\hline$(-0.2,1.2)$ & 4.8426 & 2.9534 & 2.8221 & 1.9792 & 2.4166 & 2.1194 \\
\hline$(-0.1,1.1)$ & 4.6399 & 2.7741 & 2.7878 & 1.9483 & 2.5850 & 1.9903 \\
\hline$(0.0,1.0)$ & 4.4371 & 2.6064 & 2.7534 & 1.9261 & 2.7534 & 1.8876 \\
\hline$(0.1,0.9)$ & 4.2344 & 2.4528 & 2.7190 & 1.9127 & 2.9218 & 1.8157 \\
\hline$(0.2,0.8)$ & 4.0316 & 2.3160 & 2.6847 & 1.9084 & 3.0901 & 1.7785 \\
\hline$(0.3,0.7)$ & 3.8289 & 2.1991 & 2.6503 & 1.9132 & 3.2585 & 1.7780 \\
\hline$(0.4,0.6)$ & 3.6262 & 2.1056 & 2.6159 & 1.9270 & 3.4269 & 1.8144 \\
\hline$(0.5,0.5)$ & 3.4234 & 2.0386 & 2.5815 & 1.9497 & 3.5953 & 1.8854 \\
\hline$(0.6,0.4)$ & 3.2207 & 2.0008 & 2.5472 & 1.9810 & 3.7636 & 1.9874 \\
\hline$(0.7,0.3)$ & 3.0179 & 1.9938 & 2.5128 & 2.0205 & 3.9320 & 2.1158 \\
\hline$(0.8,0.2)$ & 2.8152 & 2.0179 & 2.4784 & 2.0676 & 4.1004 & 2.2663 \\
\hline$(0.9,0.1)$ & 2.6124 & 2.0721 & 2.4441 & 2.1219 & 4.2688 & 2.4347 \\
\hline$(1.0,0.0)$ & 2.4097 & 2.1542 & 2.4097 & 2.1829 & 4.4371 & 2.6175 \\
\hline$(1.1,-0.1)$ & 2.2070 & 2.2610 & 2.3753 & 2.2500 & 4.6055 & 2.8120 \\
\hline$(1.2,-0.2)$ & 2.0042 & 2.3892 & 2.3410 & 2.3226 & 4.7739 & 3.0158 \\
\hline$(1.3,-0.3)$ & 1.8015 & 2.5357 & 2.3066 & 2.4003 & 4.9423 & 3.2273 \\
\hline$(1.4,-0.4)$ & 1.5987 & 2.6974 & 2.2722 & 2.4826 & 5.1106 & 3.4450 \\
\hline
\end{tabular}

Note: (1) The numbers in the bracket at column ' $\left(w_{1}, w_{2}\right)$ ' denote the 19 weights combinations for the 19 weight-based portfolios. (2) $r_{p}$ and $\sqrt{h_{p}}$ respectively denote the mean return and mean volatility of the above weight-based portfolios for the in-sample or estimate period, and are obtained from the CW method. (3) Bold font in column ' $\sqrt{h_{p}}$ ' denotes the smallest level of volatility among all 19 weight-based portfolios. (4) Shade font in column ' $r_{p}$ ' denotes the return set of portfolios on the efficient frontier based on the volatility type of risk measure.

Owing to the limited space, Table 4 only lists the mean values of the return and volatility of 19 weight-based portfolios during the estimate period for three oil market portfolios by using the $\mathrm{CW}$ method, and the data for the others market types of portfolios are available upon request. Figure 1 illustrates the relation between return and volatility for three oil market portfolios. From each of subfigures of Figure 1, I observe a curve connecting the 19 points corresponding to the 19 weight-based portfolios has the shape of a parabolic on the risk-return space. For example, the return and volatility data of 19 weight-based portfolios listed in columns 'WTI-GasNyh', 'WTI-Heating', and 'GasNyh-Heating' of Table 4 are used to plot a parabolic curve in Figure 1a-c, respectively. The portfolio at the nose of the parabolic curve is the minimum variance portfolio (MVP) because it has the minimum risk among the 19 weight-based portfolios. The efficient frontier is on the upper-right portion of the MVP of parabolic curve, and all the weight-based portfolios on the efficient frontier are effective. On the contrary, all the weight-based portfolios on the lower-right portion of the MVP of parabolic curve are ineffective. From Table 4, I can observe that, regarding the WTI-GasNyh portfolio, the portfolio corresponding to the weight combination $\left(w_{1}=0.7\right.$, and $\left.w_{2}=0.3\right)$ has the smallest level of volatility (1.9938) among the 19 weight-based portfolios, suggesting that $w_{1}^{M V P}=0.7$ and $w_{2}^{M V P}=0.3$ are the weight combination of portfolio on the nose of efficient frontier, the MVP, for this bi-component assets portfolio. Moreover, $\mathrm{w}_{1} \leq 0.7\left(=w_{1}^{M V P}\right)$ and $w_{2} \geq 0.3\left(=w_{2}^{M V P}\right)$ respectively are the weight range of the first and second component assets of all portfolios on the efficient frontier because the portfolios corresponding to the weight range $w_{1}<0.7$ ( or $w_{2}>0.3$ ) have the greater return than those corresponding to the weight range $w_{1}>0.7$ (or $w_{2}<0.3$ ). By the same inference process, for the WTI-Heating portfolio, $w_{1}^{M V P}=0.2$ and $w_{2}^{M V P}=0.8$ are the weight combination of $\mathrm{MVP}$, and $w_{1} \leq 0.2$ and $w_{2} \geq 0.8$ respectively are the weight range of the first and second component assets of all portfolios on the efficient frontier. For the GasNyh-Heating portfolio, $w_{1}^{M V P}=0.3$ and $w_{2}^{M V P}=0.7$ are the weight combination of MVP, and $w_{1} \geq 0.3$ and $w_{2} \leq 0.7$ respectively are the weight range of the first and second component assets of all portfolios on the efficient frontier. Subsequently, for the three oil market portfolios, the messages of the efficient frontier are summarized in Panel A of Table 5. The above messages include the MVP weight combination $\left(w_{1}^{M V P}\right.$ and $\left.w_{2}^{M V P}\right)$ and its 
corresponding return $\left(r_{p}^{M V P}\right)$ and volatility $\left(\sqrt{h_{p}^{M V P}}\right)$, and the weight range of component assets of all portfolios on the efficient frontier (e.g., $w_{1} \leq w_{1}^{M V P}$ for WTI-GasNyh portfolio). By imitating the above-mentioned process, Panels B-E of Table 5 summarize the messages of the efficient frontier for the three stock market portfolios, nine mixed oil-stock market portfolios, three mixed oil-FX market portfolios, and three mixed stock-FX market portfolios, respectively. Moreover, Table 5 also lists the values of coefficient of variation (CV) for the above-mentioned MVPs.

Table 5. The messages of efficient frontier got from the constant weight (CW) approach for five market types of portfolios.

\begin{tabular}{|c|c|c|c|c|c|c|c|c|}
\hline & Weight Range & $\left(w_{1}^{M V P}, w_{2}^{M V P}\right)$ & $r_{p}^{M V P}$ & $\sqrt{h_{p}^{M V P}}$ & $C V^{M V P}$ & Diff & Sum & SUM \\
\hline \multicolumn{9}{|c|}{ Panel A. Oil market portfolios } \\
\hline WTI-GasNyh & $w_{1} \leq w_{1}^{M V P}(=0.7)$ & $(0.7,0.3)$ & 3.0179 & $1.9938(20)$ & $0.660(12)$ & 8 & 32 & $40(14)$ \\
\hline WTI-Heating & $w_{1} \leq w_{1}^{M V P}(=0.2)$ & $(0.2,0.8)$ & 2.6847 & $1.9084(19)$ & $0.710(14)$ & 5 & 33 & $38(13)$ \\
\hline GasNyh-Heating & $w_{1} \geq w_{1}^{M V P}(=0.3)$ & $(0.3,0.7)$ & 3.2585 & $1.7780(18)$ & $0.545(9)$ & 9 & 27 & $36(12)$ \\
\hline \multicolumn{9}{|c|}{ Panel B. Stock market portfolios } \\
\hline SP500-DJ & $w_{1} \leq w_{1}^{M V P}(=0.2)$ & $(0.2,0.8)$ & 1.3602 & $0.7209(11)$ & $0.529(8)$ & 3 & 19 & 22(5) \\
\hline SP500-Nasdaq & $w_{1} \geq w_{1}^{M V P}(=1.1)$ & $(1.1,-0.1)$ & 1.2851 & $0.6750(6)$ & $0.525(7)$ & 1 & 13 & $14(1)$ \\
\hline DJ-Nasdaq & $w_{1} \geq w_{1}^{M V P}(=1.2)$ & $(1.2,-0.2)$ & 1.4288 & $0.7191(10)$ & 0.503(3) & 7 & 13 & $20(4)$ \\
\hline \multicolumn{9}{|c|}{ Panel C. Mixed oil-stock market portfolios } \\
\hline WTI-SP500 & $w_{1} \geq w_{1}^{M V P}(=0.0)$ & $(0.0,1.0)$ & 1.2726 & $0.7294(14)$ & $0.573(10)$ & 4 & 24 & $28(8)$ \\
\hline WTI-DJ & $w_{1} \geq w_{1}^{M V P}(=0.0)$ & $(0.0,1.0)$ & 1.3821 & $0.7187(9)$ & $0.520(6)$ & 3 & 15 & $18(3)$ \\
\hline WTI-Nasdaq & $w_{1} \geq w_{1}^{\mathrm{MVP} P}(=0.1)$ & $(0.1,0.9)$ & 1.2746 & $0.9112(17)$ & $0.714(15)$ & 2 & 32 & $34(11)$ \\
\hline GasNyh-SP500 & $w_{1} \geq w_{1}^{M V P}(=0.1)$ & $(0.1,0.9)$ & 1.5891 & $0.7248(13)$ & $0.456(1)$ & 12 & 14 & $26(7)$ \\
\hline GasNyh-DJ & $w_{1} \geq w_{1}^{M V P}(=0.0)$ & $(0.0,1.0)$ & 1.3821 & $0.7162(7)$ & $0.518(5)$ & 2 & 12 & $14(1)$ \\
\hline GasNyh-Nasdaq & $w_{1} \geq w_{1}^{M V P}(=0.1)$ & $(0.1,0.9)$ & 1.4773 & $0.8821(15)$ & $0.597(11)$ & 4 & 26 & $30(9)$ \\
\hline Heating-SP500 & $w_{1} \geq w_{1}^{M V P}(=0.1)$ & $(0.1,0.9)$ & 1.4207 & $0.7247(12)$ & $0.510(4)$ & 8 & 16 & $24(6)$ \\
\hline Heating-DJ & $w_{1} \geq w_{1}^{M V P}(=0.1)$ & $(0.1,0.9)$ & 1.5192 & $0.7179(8)$ & $0.472(2)$ & 6 & 10 & $16(2)$ \\
\hline Heating-Nasdaq & $w_{1} \geq w_{1}^{M V P}(=0.1)$ & $(0.1,0.9)$ & 1.3090 & $0.8888(16)$ & $0.678(13)$ & 3 & 29 & $32(10)$ \\
\hline \multicolumn{9}{|c|}{ Panel D. Mixed oil-FX market portfolios } \\
\hline WTI-UDI & $w_{1} \geq w_{1}^{M V P}(=0.1)$ & $(0.1,0.9)$ & -0.0147 & 0.4265 & NA & - & - & - \\
\hline GasNyh-UDI & $w_{1} \geq w_{1}^{M V P}(=0.1)$ & $(0.1,0.9)$ & 0.1880 & $0.4616(5)$ & $2.455(18)$ & 13 & 23 & $36(12)$ \\
\hline Heating-UDI & $w_{1} \geq w_{1}^{M V P}(=0.1)$ & $(0.1,0.9)$ & 0.0196 & $0.4340(2)$ & 22.14(19) & 17 & 21 & $38(13)$ \\
\hline \multicolumn{9}{|c|}{ Panel E. Mixed stock-FX market portfolios } \\
\hline SP500-UDI & $w_{1} \geq w_{1}^{M V P}(=0.3)$ & $(0.3,0.7)$ & 0.1829 & $0.4383(3)$ & $2.396(17)$ & 14 & 20 & $34(11)$ \\
\hline DJ-UDI & $w_{1} \geq w_{1}^{M V P}(=0.3)$ & $(0.3,0.7)$ & 0.2157 & $0.4332(1)$ & $2.008(16)$ & 15 & 17 & $32(10)$ \\
\hline Nasdaq-UDI & $w_{1} \geq w_{1}^{M V P}(=0.2)$ & $(0.2,0.8)$ & 0.0024 & $0.4611(4)$ & 192.1(20) & 16 & 24 & $30(9)$ \\
\hline
\end{tabular}

Note: (1) The numbers in columns ' $r_{p}^{M V P}$ ' and ' $\sqrt{h_{p}^{M V P}}$ ' respectively denote the mean return and mean volatility of portfolio at the efficient frontier's nose (i.e., the minimum variance portfolio, MVP) that are obtained by the CW approach. (2) The numbers in the bracket at column ' $\left(w_{1}^{M V P}, w_{2}^{M V P}\right)$ ' denote the corresponding weights combination for the above MVP. (3) The inequality expression in column 'weight range' denotes the weight range of first component asset of all portfolios on the efficient frontier. For example, the portfolios on the efficient frontier are on the side $w_{1} \leq 0.7$ where $w_{1}^{M V P}=0.7$ for the WTI-GasNyh portfolio. The results in columns ' $r_{p}^{M V P}$ ', ' $\sqrt{h_{p}^{M V P}}$ ', ' $\left(w_{1}^{M V P}, w_{2}^{M V P}\right)$ ' and 'weight range' are obtained by the $\mathrm{CW}$ approach, and are summarized from Table 4 . (4) $\mathrm{CV}$ denotes the coefficient of variation, and is the ratio of the standard deviation or volatility to the return. (5) Shade (respectively, bold) font in columns ' $r_{p}^{M V P}$ ' ' $\sqrt{h_{p}^{M V P}}$ ' and ' $C V^{M V P}$ ' respectively denotes the greatest (respectively, smallest) value of $r_{p}^{M V P}$, and the smallest (respectively, greatest) level of $\sqrt{h_{p}^{M V P}}$ and $C V^{M V P}$ among

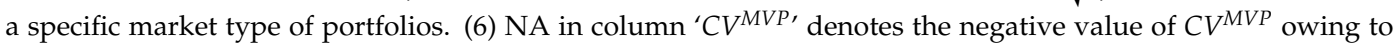
negative value of return, indicating that this portfolio is meaningless. (7) The numbers in the bracket at the column ' $\sqrt{h_{p}^{M V P}}$ (respectively, ' $C V^{M V P}$ ') denote the rank-order numbers from the smallest to the greatest when all the values of volatility (respectively, CV) for 21 bi-component portfolios are compared each other. That is, the numbers ' 1 ' and ' $21^{\prime}$ in the bracket of column ' $\sqrt{h_{p}^{M V P}}$ ' (respectively, ' $C V^{M V P}$ ') corresponding to a specific bi-component portfolio respectively denote the above bi-component portfolio has the smallest and greatest value of volatility (respectively, ' $C V^{\prime}$ ') among 21 bi-component portfolios. (8) The numbers in column 'diff' (respectively, 'sum') denote the difference in absolute value (respectively, sum) of two different numbers of rank-order respectively corresponding to the volatility and CV types of risk measure. (9) The numbers in column 'SUM' denote the sum of values of 'diff' and 'sum' at the same row and the numbers in the bracket at the column 'SUM' denote the rank-order numbers from the smallest to the greatest when all the values of SUM for 21 bi-component portfolios are compared each other. 


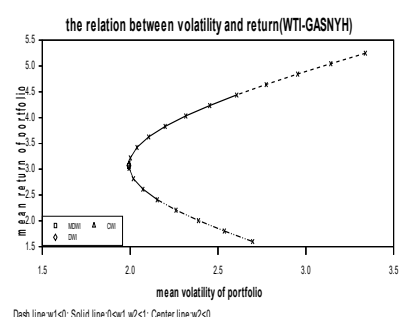

(a) WTI-Gasnyh

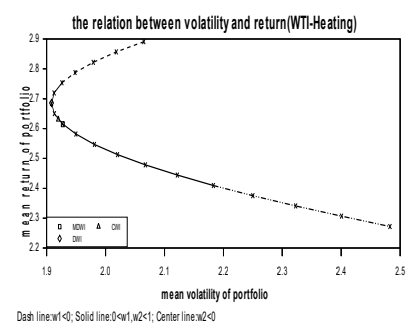

(b) WTI-Heating

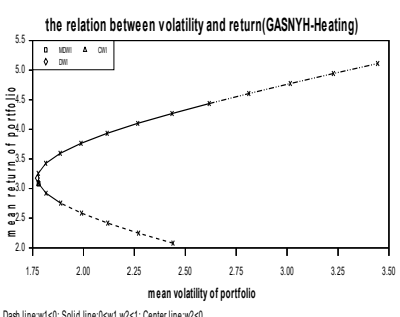

(c) Gasnyh-Heating

Figure 1. The relation between return and volatility of 19 weight-based portfolios for three oil market portfolios.

Via using the $\mathrm{CW}$ method, Table 5 reports the messages of efficient frontier for the five market types of portfolios or $21 \mathrm{bi}$-component asset portfolios. The messages of efficient frontier include the weight range of component assets of all portfolios on the efficient frontier and the messages of MVP, the weight combination, return, volatility and CV on the MVP. Notably, the CV and volatility risk measures are suited for the investors who are willing or not willing to bear the risk, respectively. Thus, via using 'the values of volatility and CV on 21 MVPs' I can select one suitable bi-component assets portfolio among 21 bi-component asset portfolios for the two types of investors. In other words, among a group of portfolios with the positive return, the investors who are willing or not willing to bear the risk should choose the portfolio with minimum CV and volatility values, respectively. Before I perform the above process of asset selection, I must do a preliminary analysis of 21 bi-component asset portfolios by using the values of return and volatility on the 21 MVPs. From Table 5, I find that, for three oil market portfolios, the values of return of MVP are between 2.6847 (WTI-Heating) and 3.2585 (GasNyh-Heating) and the levels of volatility of MVP range from 1.7780 (GasNyh-Heating) to 1.9938 (WTI-GasNyh). Moreover, for three stock market portfolios and nine mixed oil-stock market portfolios the values of return of MVP are between 1.2726 (WTI-SP500) and 1.5891 (GasNyh-SP500) and the levels of volatility of MVP range from 0.6750 (SP500-Nasdaq) to 0.9112 (WTI-Nasdaq). Furthermore, for three mixed oil-FX market portfolios and three mixed stock-FX market portfolios, the values of return of MVP are between -0.0147 (WTI-UDI) and 0.2157 (DJ-UDI) and the levels of volatility of MVP range from 0.4265 (WTI-UDI) to 0.4616 (GasNyh-UDI). Since the ranges of return and volatility are overlapped for three stock market portfolios and nine mixed oil-stock market portfolios, this study regards these two market types of portfolios as a whole when I analyze the portfolio's efficiency. The phenomenon also appears in the three mixed oil-FX market portfolios and three mixed stock-FX market portfolios. These results indicate that the oil market portfolios have the largest value of return and the highest level of risk whereas the mixed oil-FX market portfolios and the mixed stock-FX market portfolios have the smallest value of return and the lowest level of risk. As to the stock market portfolios and the mixed oil-stock market portfolios, they have the intermediate value of return and the middle level of risk. Figure 2 can show the above phenomenon. Figure 2 depicts the relative location of MVPs for five market types of portfolios, or 21 bi-component asset portfolios on the risk-return space. Based on the above findings, I can find that among five market types of portfolios the mixed oil-FX market portfolios and the mixed stock-FX market portfolios are the relative minimum-variance portfolios whereas the oil market portfolios are the relative maximum-variance portfolios. The relative minimum-variance (respectively, maximum-variance) portfolios are a group of portfolios or a specific market type of portfolios, and most of portfolios within this group own the almost smallest (respectively, largest) level of volatility among 21 MVPs. On the contrary, the relatively most efficient (respectively, inefficient) portfolios are a group of portfolios or a specific market type of portfolios, and most of portfolios within this group own the almost smallest (respectively, largest) value of $\mathrm{CV}$ among $21 \mathrm{MVPs}$. The relative minimum-variance portfolios are suited for the investors who are not willing to bear the risk. On the other hand, the relatively most efficient portfolios are the 
best portfolios for the investors who are willing to bear the risk. Notably, for a group of portfolios such as 21 MVPs the relative minimum-variance portfolios and the relatively most efficient portfolios belong to effective portfolios because these two groups of portfolio are respectively similar with two portfolios of the efficient frontier for a bi-component asset portfolio such as the MVP and a portfolio with the minimum value of $\mathrm{CV}$. However, I cannot decide which market type of portfolios are the relatively most efficient portfolios. Hence, I rank each MVP and give an order number according to that MVP's volatility or CV value within the $21 \mathrm{MVPs}$ of 21 bi-component asset portfolios from the smallest value to the largest value. Then the numbers in the bracket beside volatility and CV value in columns $\sqrt{h_{p}^{M V P}}$ and $\mathrm{CV}$ of Table 5 are the rank-order numbers via the above comparison results. That is, the smaller the rank-order number for $\sqrt{h_{p}^{M V P}}$ (respectively, CV), the lower the risk (respectively, risk per unit return).

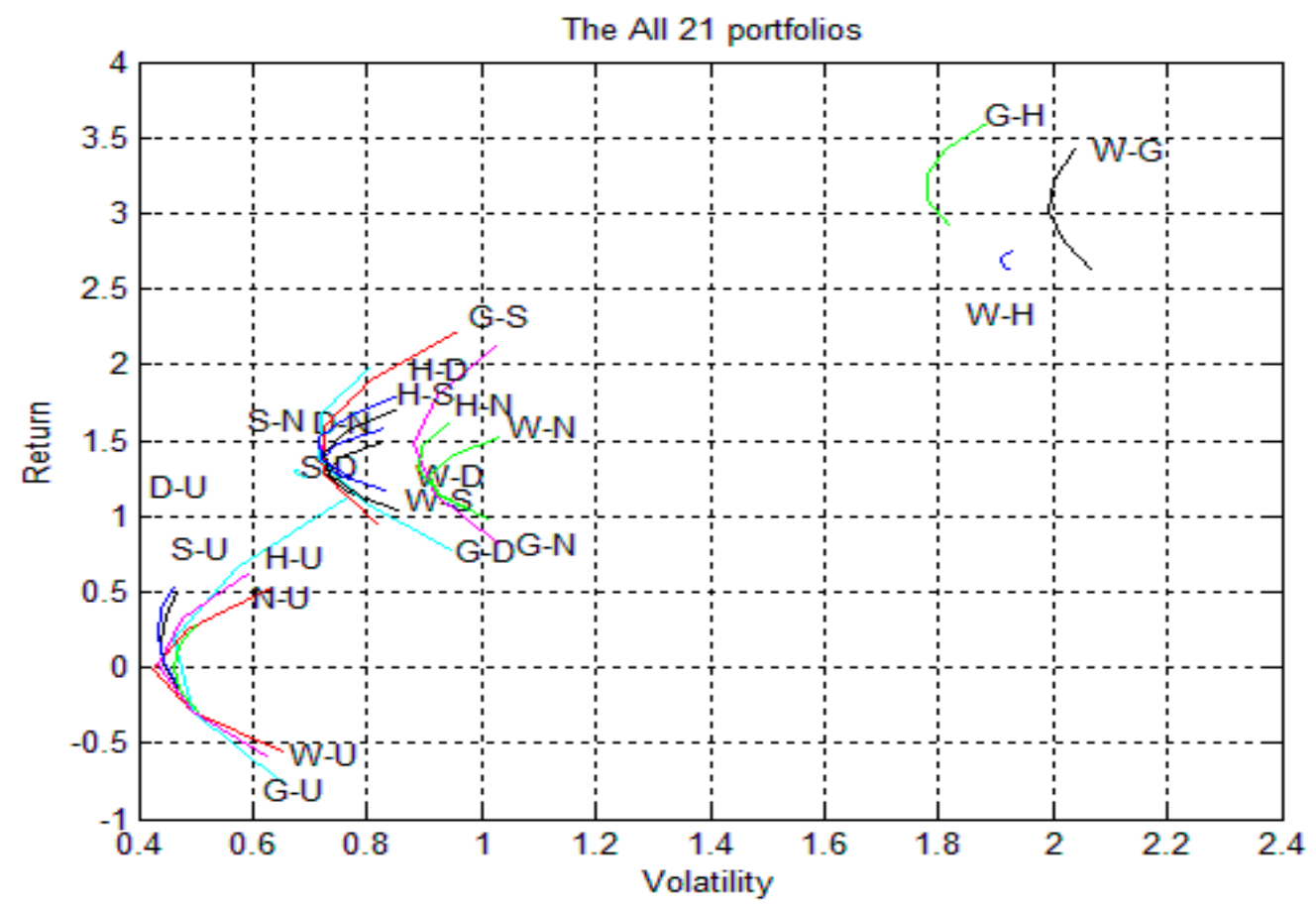

Figure 2. The relative location of efficient frontier's nose for 21 bi-component portfolios. Note: In this figure, ' $W^{\prime}$, ' $G$ ', ' $\mathrm{H}^{\prime},{ }^{\prime} \mathrm{S}^{\prime}, \mathrm{C}^{\prime}$, ' $\mathrm{N}$ ', and 'U' denote the West Texas intermediate (WTI), GasNyh, Heating, SP500, DJ, Nasdaq, and UDI, respectively. Hence, ' $\mathrm{G}-\mathrm{H}^{\prime}$ denotes a bi-component portfolio that is constructed by the GasNyh and Heating.

Subsequently, via using the rank-order number for $\sqrt{h_{p}^{M V P}}$ I can select one suitable bi-component assets portfolio among $21 \mathrm{bi}$-component asset portfolios for the investors who are not willing to bear the risk. As shown in Table 5, I can observe that, based on the volatility risk measure, the rank-order numbers $1 \sim 5$ are all distributed in the mixed oil-FX market portfolios (e.g., 2,5) and mixed stock-FX market portfolios (e.g., 1,3,4) whereas the rank-order numbers 18 20 are all distributed at the oil market portfolios. The above results indicate that both the mixed oil-FX market portfolios and mixed stock-FX market portfolios are the relative minimum-variance portfolios whereas the oil market portfolios are the relative maximum-variance portfolios. These results are consistent with those found at the previous paragraph. Notably, regarding both the mixed oil-FX market portfolios and mixed stock-FX market portfolios, the relative minimum-variance portfolios, the rank-order numbers based on the $\mathrm{CV}$ risk measure greatly increase. For example, regarding the DJ-UDI (respectively, Heating-UDI) portfolio the rank-order number for the volatility risk measure is one (respectively, 2) but this number for the CV risk measure increases to 16 (respectively, 19). Notably, the DJ-UDI portfolio is the global 
minimum-variance portfolio that is suited for the investors who are not willing to bear the risk. Among the $21 \mathrm{MVPs}$, the global minimum-variance (respectively, maximum variance) portfolio has the smallest (respectively, largest) level of volatility. Conversely, the global most efficient (respectively, inefficient) portfolio owns the smallest (respectively, largest) value of risk per unit return (CV) among the 21 MVPs. On the other hand, via using the rank-order number for CV I can select one suitable bi-component assets portfolio among 21 bi-component asset portfolios for the investors who are willing to bear the risk. Based on the $\mathrm{CV}$ risk measure, the rank-order numbers 1 8 are all distributed at the mixed oil-stock market portfolios (e.g., 1,2,4,5,6) and stock market portfolios (e.g., 3,7,8) whereas the rank-order numbers 16 20 are all distributed at the mixed oil-FX market portfolios (e.g., 18, 19) and mixed stock-FX market portfolios (e.g., 16, 17, 20). These results indicate that both the mixed oil-stock market portfolios and stock market portfolios seem to be the relatively most efficient portfolios whereas both the mixed oil-FX market portfolios and stock-FX market portfolios are the relative most inefficient portfolios. Notably, regarding both the mixed oil-stock market portfolios and stock market portfolios, the relatively most efficient portfolios, the rank-order numbers based on the volatility risk measure greatly increase. For example, regarding GasNyh-SP500 (respectively, Heating-DJ) portfolio the rank-order number for the $\mathrm{CV}$ risk measure is one (respectively, 2) but this number for the volatility risk measure increases to 13 (respectively, 8). Notably, the GasNyh-SP500 portfolio is the global most efficient portfolio that is suited for the investors who are willing to bear the risk.

From the above findings, it is hard to select the optimal portfolio because if I choose the relative minimum-variance portfolios such as the global minimum-variance portfolio (DJ-UDI) then I will face the greater risk per unit return. Because regarding the DJ-UDI portfolio the rank-order number for the volatility risk measure is one but this number for the $\mathrm{CV}$ risk measure increases to 16 . On the other hand, if I select the relatively most efficient portfolios such as the global most efficient portfolio (GasNyh-SP500) then I will face the greater risk. Because regarding the GasNyh-SP500 portfolio the rank-order number for the $\mathrm{CV}$ risk measure is one but this number for the volatility risk measure increases to 13. Hence, I propose an asset selection criterion, based on the values of 'difference' and 'sum' of two different rank-order numbers respectively corresponding to the volatility and CV risk measures, to select the suitably effective portfolio. The asset selection criterion is first to rank the values of the volatility on MVPs of all possible component-based portfolios from the smallest to largest, then to give a rank order number for each component-based portfolio and so is the $\mathrm{CV}$. Because the greater the value of the 'difference' of the two rank-order numbers respectively corresponding for the volatility and $\mathrm{CV}$ risk measures, the larger the variation of rank-order numbers for two types of risk measure. On the contrary, the greater the value of the 'sum' of the two rank-order numbers respectively corresponding for the volatility and $\mathrm{CV}$ risk measures, the greater the risk. Hence, the smaller the values of the above 'difference' and 'sum' a portfolio has, the better the performance the portfolio owns. This rule can infer that the smaller the value of the summation of the above 'difference' and 'sum' a portfolio owns, the better the performance the portfolio has. The values in column 'SUM' of Table 5 are the summation of the above 'difference' and 'sum' values a portfolio has. Subsequently, I rank each portfolio and give an order number according to the above 'SUM' value within 21 bi-component asset portfolios from the smallest value to the largest value. As reported at the rank-order numbers in column 'SUM' of Table 5, both the SP500-Nasdaq $\left(w_{1} \geq w_{1}^{M V P}=1.1\right)$ and GasNyh-DJ $\left(w_{1} \geq w_{1}^{M V P}=0.0\right)$ are the most suitable bi-component asset portfolios because the rank-order number of these two portfolio is one. The inequality expression in the bracket beside the above bi-component asset portfolios denotes the weight range of first component assets of all portfolios on the efficient frontier based on the $\mathrm{CW}$ approach. Notably, the SP500-Nasdaq and GasNyh-DJ portfolios respectively belong to the stock market portfolios and the mixed oil-stock market portfolios, which are the relatively most efficient portfolios. It is worth noting that the asset selection criterion is a compromise method in the portfolio picking process for two types of investors who are willing or not willing to bear the risk because the above process produces the contradictory results when using the $\mathrm{CV}$ and volatility risk measures. 


\subsubsection{The Forecast Performance Comparison for Three Developed Capital Allocation Approaches}

As reported in the previous subsection, the $\mathrm{CW}$ type of capital allocation $(\mathrm{CW})$ can find all the messages of efficient frontier for all $21 \mathrm{bi}$-component asset portfolios. The above messages include the weight range of component assets of all portfolios on the efficient frontier and all the messages of MVP such as $w_{1}^{M V P}, w_{2}^{M V P}, r_{p}^{M V P}, \sqrt{h_{p}^{M V P}}$ and $C V^{M V P}$. Notably, the MVP is the start point of efficient frontier, and thus it owns the smallest value of volatility among all portfolios on the efficient frontier. Hence, for each of 21 bi-component asset portfolios, the CW approach must calculate the values of both return and volatility corresponding to a group of weight-based portfolios such as 19 weighted-based portfolios in this study. The MVP is the weight-based portfolio that has the smallest level of volatility among 19 weighted-based portfolios. Thus, the CW approach is time consuming and is not accurate that ever mentioned at Section 3.2. Hence, this study proposes the other three capital allocation approaches, the CWI, DWI and MDWI, to find all the messages of MVP for each of 21 bi-component asset portfolios quickly and precisely. Subsequently, this study regards the MVP obtained through the CW approach as the benchmark, and then evaluates the forecast performance for these three developed capital allocation approaches by using the portfolio efficiency criterion based on two different types of risk measure.

To compare the forecast performance of the three developed capital allocation approaches in this study, I compare the values of both volatility and return of MVPs obtained from the DWI, MDWI and CWI with those got from the CW. Subsequently, this study utilizes the above comparison results to explore whether the MVPs obtained from these three developed capital allocation approaches have the better portfolio's efficiency than the MVP got from the CW and if so, which of these three approaches has the best forecast performance? For all 21 bi-component asset portfolios, Table 6 reports the values of both return and volatility of MVPs got from the CW approach, and those of MVP obtained from the three developed capital allocation approaches, the MDWI, DWI and CWI. Subsequently, when the performance comparison for these three developed capital allocation approaches is performed then four types of comparison results appear in Table 6. For example, regarding the WTI-GasNyh portfolio in Table 6, the value of the return of MVP got from the MDWI (3.0630) is greater than that derived from the CW (3.0179), and the level of volatility of MVP obtained from the MDWI (1.9926) is lower than that derived from the CW (1.9938). This result indicates that the MDWI is superior to the CW since the MVP got from the MDWI exhibits a higher return and a lower risk as compared with the CW. In this case, I record the result of the performance comparison as the symbol " $\mathrm{O}$ " in column $\mathrm{C}$ and row MDWI of WTI-GasNyh portfolio in Table 6 and in the cell corresponding to column W-G and row MDWI in Panel A of Table 7. This is the first type of comparison result. Moreover, for the GasNyh-Heating portfolio, the value of the return of MVP got from the MDWI (3.0860) is lower than that obtained from the CW (3.2585), and the level of volatility of MVP obtained from the MDWI (1.7790) is greater than that derived from the CW (1.7780). This result suggests that the MDWI is inferior to the CW since the MVP got from MDWI has a lower return and a higher risk as compared with the CW. I record this result of the performance comparison as the symbol " $\times$ " in column $C$ and row MDWI of GasNyh-Heating portfolio in Table 6 and in the cell corresponding to column G-H and row MDWI in Panel A of Table 7. This is the second type of comparison result. On the other hand, the value of the return of MVP got from for the DWI (3.1764) is lower than that gained from the CW (3.2585), whereas the level of volatility of MVP acquired from the DWI (1.7736) is lower than that gained from the CW (1.7780). It is not possible to determine which approach is superior or inferior based on the volatility risk measure since the MVP got from the DWI has a lower return and a lower risk as compared with the CW. Owing to the uncertainty in this case, I use the CV as another risk measure to resolve this problem. The value of CV of MVP got from the DWI $(0.5584=1.7736 / 3.1764)$ is greater than that gained from the CW $(0.5457=1.7780 / 3.2585)$, suggesting that the DWI is inferior to CW by virtue of the higher risk per unit of return. I record this result of the performance comparison as the symbol " $\times(?, 1)$ " in column $C$ and row DWI of GasNyh-Heating portfolio in Table 6 and in the cell corresponding to column G-H and 
row DWI in Panel A of Table 7. Notably, the symbol ' $x$ ' denotes the specific capital allocation approach is inferior to the benchmark (CW) by using the CV risk measure. In addition, the symbol '?' in the bracket represents the comparison result between the specific capital allocation and CW approaches is uncertain by using the volatility risk measure whereas the symbol ' 1 ' in the bracket denotes the MVP got from the specific capital allocation approach has a lower return and a lower risk as compared with the CW approach. This is the third type of comparison result. Furthermore, regarding the SP500-DJ portfolio, the value of the return of MVP got from the MDWI (1.4215) is higher than that obtained from the CW (1.3602), whereas the level of volatility of MVP got from the MDWI (0.7313) is higher than that obtained from the CW (0.7209). This result indicates that it is not possible to determine which approach is superior or inferior based on the volatility risk measure since the MVP got from the MDWI has a higher return and a higher risk as compared with the CW. As in the previous uncertainty case, I also use the $\mathrm{CV}$ as another risk measure to resolve this problem. The value of $\mathrm{CV}$ of MVP got from the MDWI $(0.5145=0.7313 / 1.4215)$ is lower than that obtained from the CW $(0.5300=0.7209 / 1.3602)$, suggesting that the MDWI is superior to $\mathrm{CW}$ by virtue of the lower risk per unit of return. I record this result of the performance comparison as the symbol " $\mathrm{O}(?, \mathrm{~h})$ " in column $\mathrm{C}$ and row MDWI of SP500-DJ portfolio in Table 6 and in the cell corresponding to column S-D and row MDWI in Panel A of Table 7. Notably, the symbol ' $\mathrm{O}$ ' denotes the specific capital allocation approach is superior to the benchmark (CW) by using the CV risk measure. In addition, the symbol '?' in the bracket represents the comparison result between the specific capital allocation and CW approaches is uncertain by using the volatility risk measure whereas the symbol ' $h$ ' in the bracket denotes the MVP got from the specific capital allocation approach has a higher return and a higher risk as compared with the CW approach. This is the fourth type of comparison result.

Table 6. The in-sample forecasting performance comparison for three developed capital allocation approaches.

\begin{tabular}{|c|c|c|c|c|c|c|c|c|}
\hline & $\left(w_{1}^{M V P}, w_{2}^{M V P}\right)$ & $r_{p}^{M V P}$ & $\sqrt{h_{p}^{M V P}}$ & $\mathrm{C}$ & $\left(w_{1}^{M V P}, w_{2}^{M V P}\right)$ & $r_{p}^{M V P}$ & $\sqrt{h_{p}^{M V P}}$ & $\mathrm{C}$ \\
\hline & \multicolumn{3}{|c|}{ WTI-GasNyh } & \multicolumn{5}{|c|}{ WTI-Heating } \\
\hline $\mathrm{CW}$ & $(0.7,0.3)$ & 3.0179 & 1.9938 & & $(0.2,0.8)$ & 2.6847 & 1.9084 & \\
\hline MDWI & $(0.6777,0.3222)$ & $3.0630(>)$ & $1.9926(<)$ & $\mathrm{O}$ & $(0.4031,0.5968)$ & $2.6148(<)$ & $1.9276(>)$ & $x$ \\
\hline DWI & $(0.6724,0.3275)$ & $3.0739(>)$ & $1.9926(<)$ & $\mathrm{O}$ & $(0.1973,0.8026)$ & $2.6856(>)$ & $1.9084(=)$ & $\mathrm{O}$ \\
\hline \multirow[t]{2}{*}{ CWI } & $(0.6604,0.3395)$ & $3.0981(>)$ & $1.9928(<)$ & $\mathrm{O}$ & $(0.3566,0.6433)$ & $2.6308(<)$ & $1.9199(>)$ & $x$ \\
\hline & \multicolumn{3}{|c|}{ GasNyh-Heating } & \multicolumn{5}{|c|}{ SP500-DJ } \\
\hline CW & $(0.3,0.7)$ & 3.2585 & 1.7780 & & $(0.2,0.8)$ & 1.3602 & 0.7209 & \\
\hline MDWI & $(0.1975,0.8024)$ & $3.0860(<)$ & $1.7790(>)$ & $\times$ & $(-0.3597,1.3597)$ & $1.4215(>)$ & $0.7313(>)$ & $\mathrm{O}(?, \mathrm{~h})$ \\
\hline DWI & $(0.2512,0.7487)$ & $3.1764(<)$ & $1.7736(<)$ & $\times(?, 1)$ & $(0.2418,0.7581)$ & $1.3556(<)$ & $0.7209(=)$ & $\times$ \\
\hline \multirow[t]{2}{*}{ CWI } & $(0.1946,0.8053)$ & $3.0812(<)$ & $1.7796(>)$ & $\times$ & $(-0.6261,1.6261)$ & $1.4506(>)$ & $0.7424(>)$ & $\mathrm{O}(?, \mathrm{~h})$ \\
\hline & \multicolumn{3}{|c|}{ SP500-Nasdaq } & \multicolumn{5}{|c|}{ DJ-Nasdaq } \\
\hline $\mathrm{CW}$ & $(1.1,-0.1)$ & 1.2851 & 0.6750 & & $(1.2,-0.2)$ & 1.4288 & 0.7191 & \\
\hline MDWI & $(1.1737,-0.1737)$ & $1.2942(>)$ & $0.6745(<)$ & $\mathrm{O}$ & $(1.2953,-0.2953)$ & $1.4511(>)$ & $0.7202(>)$ & $\mathrm{O}(?, \mathrm{~h})$ \\
\hline DWI & $(1.1469,-0.1469)$ & $1.2909(>)$ & $0.6743(<)$ & $\mathrm{O}$ & $(1.2136,-0.2136)$ & $1.4320(>)$ & $0.7191(=)$ & $\mathrm{O}$ \\
\hline \multirow[t]{2}{*}{ CWI } & $(1.1293,-0.1293)$ & $1.2887(>)$ & $0.6744(<)$ & $\mathrm{O}$ & $(1.2844,-0.2844)$ & $1.4485(>)$ & $0.7199(>)$ & $\mathrm{O}(?, \mathrm{~h})$ \\
\hline & \multicolumn{3}{|c|}{ WTI-SP500 } & \multicolumn{5}{|c|}{ WTI-DJ } \\
\hline $\mathrm{CW}$ & $(0.0,1.0)$ & 1.2726 & 0.7294 & & $(0.0,1.0)$ & 1.3821 & 0.7187 & \\
\hline MDWI & $(0.1301,0.8698)$ & $1.4206(>)$ & $0.7710(>)$ & $\mathrm{O}(?, \mathrm{~h})$ & $(0.1214,0.8785)$ & $1.5069(>)$ & $0.7626(>)$ & $\mathrm{O}(?, \mathrm{~h})$ \\
\hline DWI & $(0.0109,0.9890)$ & $1.2851(>)$ & $0.7290(<)$ & $\mathrm{O}$ & $(-0.0010,1.0010)$ & $1.3810(<)$ & $0.7187(=)$ & $\times$ \\
\hline \multirow[t]{2}{*}{ CWI } & $(0.1409,0.8590)$ & $1.4329(>)$ & $0.7787(>)$ & $\mathrm{O}(?, \mathrm{~h})$ & $(0.1320,0.8679)$ & $1.5178(>)$ & $0.7703(>)$ & $\mathrm{O}(?, \mathrm{~h})$ \\
\hline & \multicolumn{3}{|c|}{ WTI-Nasdaq } & \multicolumn{5}{|c|}{ GasNyh-SP500 } \\
\hline $\mathrm{CW}$ & $(0.1,0.9)$ & 1.2746 & 0.9112 & & $(0.1,0.9)$ & 1.5891 & 0.7248 & \\
\hline MDWI & $(0.2092,0.7907)$ & $1.4124(>)$ & $0.9554(>)$ & $\mathrm{O}(?, \mathrm{~h})$ & $(0.1127,0.8872)$ & $1.6295(>)$ & $0.7311(>)$ & $\mathrm{O}(?, \mathrm{~h})$ \\
\hline DWI & $(0.0754,0.9245)$ & $1.2436(<)$ & $0.9096(<)$ & $\times(?, 1)$ & $(0.0523,0.9476)$ & $1.4382(<)$ & $0.7143(<)$ & $\times(?, 1)$ \\
\hline CWI & $(0.2106,0.7893)$ & $1.4142(>)$ & $0.9564(>)$ & $\mathrm{O}(?, \mathrm{~h})$ & $(0.1153,0.8846)$ & $1.6376(>)$ & $0.7326(>)$ & $\mathrm{O}(?, \mathrm{~h})$ \\
\hline
\end{tabular}


Table 6. Cont

\begin{tabular}{|c|c|c|c|c|c|c|c|c|}
\hline & $\left(w_{1}^{M V P}, w_{2}^{M V P}\right)$ & $r_{p}^{M V P}$ & $\sqrt{h_{p}^{M V P}}$ & $\mathrm{C}$ & $\left(w_{1}^{M V P}, w_{2}^{M V P}\right)$ & $r_{p}^{M V P}$ & $\sqrt{h_{p}^{M V P}}$ & $\mathrm{C}$ \\
\hline & \multicolumn{3}{|c|}{ GasNyh-DJ } & \multicolumn{5}{|c|}{ GasNyh-Nasdaq } \\
\hline CW & $(0.0,1.0)$ & 1.3821 & 0.7162 & & $(0.1,0.9)$ & 1.4773 & 0.8821 & \\
\hline MDWI & $(0.1065,0.8934)$ & $1.7077(>)$ & $0.7229(>)$ & $\mathrm{O}(?, \mathrm{~h})$ & $(0.1739,0.8260)$ & $1.7207(>)$ & $0.9043(>)$ & $\mathrm{O}(?, \mathrm{~h})$ \\
\hline DWI & $(0.0464,0.9535)$ & $1.5241(>)$ & $0.7062(<)$ & $\mathrm{O}$ & $(0.0989,0.9010)$ & $1.4740(<)$ & $0.8821(=)$ & $\times$ \\
\hline \multirow[t]{2}{*}{ CWI } & $(0.1094,0.8905)$ & $1.7164(>)$ & $0.7244(>)$ & $\mathrm{O}(?, \mathrm{~h})$ & $(0.1696,0.8303)$ & $1.7065(>)$ & $0.9018(>)$ & $\mathrm{O}(?, \mathrm{~h})$ \\
\hline & \multicolumn{3}{|c|}{ Heating-SP500 } & \multicolumn{5}{|c|}{ Heating-DJ } \\
\hline CW & $(0.1,0.9)$ & 1.4207 & 0.7247 & & $(0.1,0.9)$ & 1.5192 & 0.7179 & \\
\hline MDWI & $(0.1685,0.8314)$ & $1.5222(>)$ & $0.7496(>)$ & $\mathrm{O}(?, \mathrm{~h})$ & $(0.1545,0.8454)$ & $1.5940(>)$ & $0.7378(>)$ & $\mathrm{O}(?, \mathrm{~h})$ \\
\hline DWI & $(0.0644,0.9355)$ & $1.3681(<)$ & $0.7214(<)$ & $\times(?, 1)$ & $(0.0572,0.9427)$ & $1.4606(<)$ & $0.7130(<)$ & $\times(?, 1)$ \\
\hline \multirow[t]{2}{*}{ CWI } & $(0.1735,0.8264)$ & $1.5297(>)$ & $0.7523(>)$ & $\mathrm{O}(?, \mathrm{~h})$ & $(0.1617,0.8382)$ & $1.6039(>)$ & $0.7415(>)$ & $\mathrm{O}(?, \mathrm{~h})$ \\
\hline & \multicolumn{3}{|c|}{ Heating-Nasdaq } & \multicolumn{5}{|c|}{ WTI-UDI } \\
\hline $\mathrm{CW}$ & $(0.1,0.9)$ & 1.3090 & 0.8888 & & $(0.1,0.9)$ & -0.0147 & 0.4265 & \\
\hline MDWI & $(0.2470,0.7529)$ & $1.5449(>)$ & $0.9147(>)$ & $\mathrm{O}(?, \mathrm{~h})$ & $(0.0875,0.9124)$ & $-0.0481(<)$ & $0.4284(>)$ & $\times$ \\
\hline DWI & $(0.1356,0.8643)$ & $1.3661(>)$ & $0.8858(<)$ & $\mathrm{O}$ & $(0.1050,0.8949)$ & $-0.0010(>)$ & $0.4263(<)$ & $\mathrm{O}$ \\
\hline \multirow[t]{2}{*}{ CWI } & $(0.2464,0.7535)$ & $1.5440(>)$ & $0.9144(>)$ & $\mathrm{O}(?, \mathrm{~h})$ & $(0.0782,0.9217)$ & $-0.0732(<)$ & $0.4312(>)$ & $\times$ \\
\hline & \multicolumn{3}{|c|}{ GasNyh-UDI } & \multicolumn{5}{|c|}{ Heating-UDI } \\
\hline $\mathrm{CW}$ & $(0.1,0.9)$ & 0.1880 & 0.4616 & & $(0.1,0.9)$ & 0.0196 & 0.4340 & \\
\hline MDWI & $(0.0626,0.9373)$ & $0.0117(<)$ & $0.4559(<)$ & $\times(?, 1)$ & $(0.0865,0.9134)$ & $-0.0212(<)$ & $0.4363(>)$ & $\times$ \\
\hline DWI & $(0.0718,0.9281)$ & $0.0549(<)$ & $0.4552(<)$ & $\times(?, 1)$ & $(0.1092,0.8907)$ & $0.0477(>)$ & $0.4335(<)$ & $\mathrm{O}$ \\
\hline \multirow[t]{2}{*}{ CWI } & $(0.0522,0.9477)$ & $-0.0373(<)$ & $0.4583(<)$ & $\times$ & $(0.0779,0.9220)$ & $-0.0472(<)$ & $0.4387(>)$ & $x$ \\
\hline & \multicolumn{3}{|c|}{ SP500-UDI } & \multicolumn{5}{|c|}{ DJ-UDI } \\
\hline $\mathrm{CW}$ & $(0.3,0.7)$ & 0.1829 & 0.4383 & & $(0.3,0.7)$ & 0.2157 & 0.4332 & \\
\hline MDWI & $(0.1969,0.8030)$ & $0.0225(<)$ & $0.4459(>)$ & $\times$ & $(0.2090,0.7909)$ & $0.0642(<)$ & $0.4405(>)$ & $\times$ \\
\hline DWI & $(0.2965,0.7034)$ & $0.1776(<)$ & $0.4383(=)$ & $\times$ & $(0.3069,0.6930)$ & $0.2273(>)$ & $0.4332(=)$ & $\mathrm{O}$ \\
\hline CWI & $(0.1592,0.8407)$ & $-0.0361(<)$ & $0.4526(>)$ & $x$ & $(0.1705,0.8294)$ & $0.0000(<)$ & $0.4473(>)$ & $x$ \\
\hline \multicolumn{9}{|c|}{ Nasdaq-UDI } \\
\hline $\mathrm{CW}$ & $(0.2,0.8)$ & 0.0024 & 0.4611 & & & & & \\
\hline MDWI & $(0.1443,0.8556)$ & $-0.0773(<)$ & $0.4644(>)$ & $\times$ & & & & \\
\hline DWI & $(0.1999,0.8000)$ & $0.0022(<)$ & $0.4611(=)$ & $\times$ & & & & \\
\hline CWI & $(0.1205,0.8794)$ & $-0.1113(<)$ & $0.4678(>)$ & $x$ & & & & \\
\hline
\end{tabular}

Note: (1) The numbers in the bracket of column ' $\left(w_{1}^{M V P}, w_{2}^{M V P}\right)$ ' corresponding to the rows CW, MDWI, DWI and CWI respectively denote the weights combination of portfolio at the nose of efficient frontier (i.e., the minimum-variance portfolio, MVP) obtained by the CW, CWI (constant weight for the in-sample period), DWI (dynamic weight for the in-sample period) and MDWI (mean of DWI) approaches. (2) The numbers in column ' $r_{p}^{M V P '}$ and ' $\sqrt{h_{p}^{M V P}}$, respectively denote the mean return and mean volatility of MVP obtained from the above-mentioned methods. (3) The numbers in columns of ' $\left(w_{1}^{M V P}, w_{2}^{M V P}\right)^{\prime}, r_{p}^{M V P '}$ and ' $\sqrt{h_{p}^{M V P}}$ ' corresponding to row ' $\mathrm{CW}$ ' are obtained from Table 5. (4) Regarding the rows 'MDWI', 'DWI' and 'CWI', the symbol $>$ (respectively, $<$ ) in the bracket beside the numbers in columns ' $r_{p}^{M V P}$ ' and ' $\sqrt{h_{p}^{M V P}}$ ' respectively denotes the values of return and volatility of MVP obtained by the MDWI, DWI and CWI are greater (respectively, lower) than those obtained by the CW. (5) The symbol O (respectively, $X$ ) in column ' $C$ ' denotes the performance of MVP obtained by the specific capital allocation approach is superior (respectively, inferior) to that gotten from the $\mathrm{CW}$ via the criteria of portfolio efficiency. (6) The symbols ' $X(?, 1)$ ' and ' $\mathrm{O}(?, \mathrm{~h})$ ' in column ' $\mathrm{C}$ ' denote that based on volatility type of risk measure the result of performance competition is uncertain as shown by the symbol '?' in the bracket. The symbol ' 1 ' (respectively, ' $\mathrm{h}$ ') in the bracket denotes the values of return and volatility of MVP obtained by a specific capital allocation approach are all lower (respectively, higher) than those obtained by the CW. However, the symbol ' $x$ ' (respectively, ' $O$ ') denotes that the performance of MVP gotten from the corresponding capital allocation approach is inferior (respectively, superior) to that gotten from the CW by using the CV type of risk measure.

Table 7. Summary results of in-sample forecasting performance comparison for three developed capital allocation approaches.

\begin{tabular}{ccccccccc}
\hline \multicolumn{7}{c}{ Panel A. Oil and Stock Markets Portfolios } \\
\hline & $\boldsymbol{W}-\boldsymbol{G}$ & $\boldsymbol{W}-\boldsymbol{H}$ & $\boldsymbol{G}-\boldsymbol{H}$ & $\boldsymbol{S}-\boldsymbol{D}$ & $\boldsymbol{S}-\boldsymbol{N}$ & $\boldsymbol{D}-\boldsymbol{N}$ & Sum1 & Sum2 \\
\hline MDWI & $\mathrm{O}$ & $\times$ & $\times$ & $\mathrm{O}(?, \mathrm{~h})$ & $\mathrm{O}$ & $\mathrm{O}(?, \mathrm{~h})$ & 4 & 2 \\
DWI & $\mathrm{O}$ & $\mathrm{O}$ & $\times(?, \mathrm{l})$ & $\times$ & $\mathrm{O}$ & $\mathrm{O}$ & 4 & 2 \\
CWI & $\mathrm{O}$ & $\times$ & $\times$ & $\mathrm{O}(?, \mathrm{~h})$ & $\mathrm{O}$ & $\mathrm{O}(?, \mathrm{~h})$ & 4 & 2 \\
\hline
\end{tabular}


Table 7. Cont.

\begin{tabular}{|c|c|c|c|c|c|c|c|c|c|c|c|}
\hline \multicolumn{12}{|c|}{ Panel B. Mixed Oil-Stock Market Portfolios } \\
\hline & $W-S$ & $W-D$ & $W-N$ & $G-S$ & $G-D$ & $G-N$ & $H-S$ & $H-D$ & $H-N$ & & \\
\hline MDWI & $\mathrm{O}(?, \mathrm{~h})$ & $\mathrm{O}(?, \mathrm{~h})$ & $\mathrm{O}(?, \mathrm{~h})$ & $\mathrm{O}(?, \mathrm{~h})$ & $\mathrm{O}(?, \mathrm{~h})$ & $\mathrm{O}(?, \mathrm{~h})$ & $\mathrm{O}(?, \mathrm{~h})$ & $\mathrm{O}(?, \mathrm{~h})$ & $\mathrm{O}(?, \mathrm{~h})$ & 9 & 0 \\
\hline DWI & $\mathrm{O}$ & $\times$ & $\times$ & $\times$ & $\mathrm{O}$ & $\times$ & $\times(?, 1)$ & $\times$ & $\mathrm{O}$ & 3 & 6 \\
\hline CWI & $\mathrm{O}(?, \mathrm{~h})$ & $\mathrm{O}(?, \mathrm{~h})$ & $\mathrm{O}(?, \mathrm{~h})$ & $\mathrm{O}(?, \mathrm{~h})$ & $\mathrm{O}(?, \mathrm{~h})$ & $\mathrm{O}(?, \mathrm{~h})$ & $\mathrm{O}(?, \mathrm{~h})$ & $\mathrm{O}(?, \mathrm{~h})$ & $\mathrm{O}(?, \mathrm{~h})$ & 9 & 0 \\
\hline \multicolumn{12}{|c|}{ Panel C. Mixed Oil-FX and Stock-FX Markets Portfolios } \\
\hline & $W-U$ & $G-U$ & $H-U$ & $S-U$ & $D-U$ & $N-U$ & & & & & \\
\hline MDWI & $\times$ & $\times(?, 1)$ & $\times$ & $\times$ & $\times$ & $\times$ & & & & $0(13)$ & $6(8)$ \\
\hline DWI & $\mathrm{O}$ & $\times(?, 1)$ & $\mathrm{O}$ & $\times$ & $\mathrm{O}$ & $\times$ & & & & $3(10)$ & 3(11) \\
\hline CWI & $x$ & $\times$ & $\times$ & $x$ & $\times$ & $\times$ & & & & $0(13)$ & $6(8)$ \\
\hline
\end{tabular}

Note: (1) Regarding the bi-component portfolios in this table, the abbreviations ' $W$ ', ' $G$ ', and ' $H$ ' respectively denote the WTI, GasNyh, and Heating in the US Oil market; the abbreviations ' $\mathrm{S}$ ', ' $\mathrm{D}$ ', and ' $\mathrm{N}$ ' respectively denote the SP500, DJ, and Nasdaq indices in the US Stock market; and the abbreviation ' $U$ ' denotes the UDI in the US foreign exchange rate market. (2) The symbols $\mathrm{O}, \times, \times(?, 1)$ and $\mathrm{O}(?, \mathrm{~h})$ in this table are defined in the notes 5-7 of Table 6, and they are summarized from column ' $C$ ' in Table 6. (3) The numbers corresponding a specified capital allocation row in column Sum1 (respectively, Sum2) of each panel denote the total number of times that the symbols ' $\mathrm{O}$ ' and ' $\mathrm{O}(?, \mathrm{~h})$ ' (respectively, ' $X$ ' and ' $x(?, 1)$ ') appear in this capital allocation for a corresponding specific market portfolios. (4) The numbers in the bracket in column Sum1 (respectively, Sum2) at the panel C of this table denote the total number of times that the symbols ' $\mathrm{O}$ ' and ' $\mathrm{O}(?, \mathrm{~h})^{\prime}$ ' (respectively, ' $\mathrm{x}$ ' and ' $\left.\mathrm{x}(?, 1)^{\prime}\right)$ appear in this capital allocation for 21 bi-component portfolios.

Table 7 summarizes the results of performance comparison between each of the three developed capital allocation approaches and the benchmark approach, the $\mathrm{CW}$, for the 21 bi-component asset portfolios. From Table 7, I find that, regarding both the oil and stock markets portfolios, the total numbers of portfolios marked as " $\mathrm{O}$ " and " $\mathrm{O}(?, \mathrm{~h})$ " for the MDWI, DWI and CWI are all equal to 4, and this number ' 4 ' is recorded in any row of column Sum1 of Panel A. Moreover, regarding the mixed oil-stock market portfolios, the total numbers of portfolios marked as " $\mathrm{O}$ " and " $\mathrm{O}(?, \mathrm{~h})$ " for the MDWI, DWI and CWI are respectively equal to 9, 3 and 9, and these three numbers are recorded in the corresponding row of column Sum1 of Panel B. On the other hand, regarding both the mixed oil-FX and stock-FX markets portfolios, the total numbers of portfolios marked as " $\mathrm{O}$ " and " $\mathrm{O}(?, \mathrm{~h})$ " for the MDWI, DWI and CWI are respectively equal to 0, 3 and 0 , and these three numbers are recorded in the corresponding row of column Sum 1 of Panel C. To sum up, regarding all 21 bi-component asset portfolios, the total numbers of portfolios marked " $\mathrm{O}$ " and "O(?,h)" for the MDWI, DWI and CWI are respectively equal to 13,10 and 13 . This result indicates that both the MDWI and CWI have the best forecast performance, followed by the DWI. In other words, the DWI has the worst forecast performance among three developed capital allocation approaches. Because the greater (respectively, smaller) the total number of portfolios marked as " $\mathrm{O}$ " and " $\mathrm{O}(?, \mathrm{~h})$ " for a specific capital allocation approach, the better (respectively, worse) the performance of this specific capital allocation approach. Imitating the above procedure, for all 21 bi-component asset portfolios the total numbers of portfolios marked as " $x$ " and " $\times(?, 1)$ " for the MDWI, DWI and CWI are respectively equal to 8,11 and 8 , indicating that the DWI has the worst forecast performance, followed by the MDWI and CWI. This result is consistent with that found by evaluating the total number of portfolios marked as " $\mathrm{O}$ " and " $\mathrm{O}(?, \mathrm{~h})$ ". Hence, I am sure that among three developed capital allocation approaches the capital allocation approaches using the entire sample weight forecasts, the MDWI and CWI, have the best forecast performance whereas the capital allocation approach using the last observation sample weight forecast, the DWI, has the worst forecast performance. These results indicate that the weight forecasts of MVP obtained from the MDWI and CWI are more accurate than that got from the CW. For example, the values of $w_{1}^{M V P}$ for SP500-Nasdaq and GasNyh-DJ, the most suitable portfolios in this study, respectively are 1.1293 (respectively, 1.1) and 0.1094 (respectively, 0.0) for the CWI (respectively, CW) approach.

\subsubsection{The Implement of a Directional Weight Increment Algorithm and Its Result}

To find the weight range of component assets of all portfolios on the efficient frontier, the CW approach as mentioned above is time consuming and is not accurate. Hence, based on the weight 
combination of MVP got from three developed capital allocation approaches this study uses the features of efficient frontier to propose a directional weight increment algorithm to find rapidly and accurately the weight range of the first component asset of all portfolios on the efficient frontier. The features of efficient frontier are that the efficient frontier starts from the MVP and has a positive slope. The theory of this algorithm lists as below. The tangent lines on the efficient frontier have the positive value of slope because the portfolios on the efficient frontier is located at the upper-right side of MVP with the slope ' $\partial r_{p, t} / \partial \sqrt{h_{p, t}}=\left(r_{p, t}^{\prime}-r_{p, t}^{M V P}\right) /\left(\sqrt{h_{p, t}^{\prime}}-\sqrt{h_{p, t}^{M V P}}\right)>0^{\prime}$ where $r_{p, t}^{M V P}$ and $\sqrt{h_{p, t}^{M V P}}$ respectively are the return and volatility of MVP whereas $r_{p, t}^{\prime}$ and $\sqrt{h_{p, t}^{\prime}}$ respectively are the return and volatility of a portfolio on the efficient frontier. Notably, the value of $\sqrt{h_{p, t}^{\prime}}-\sqrt{h_{p, t}^{M V P}}$ must be positive owing to $\sqrt{h_{p, t}^{M V P}}$ having the smallest value of volatility among all portfolios on the efficient frontier. Thus, I only find out which direction of weight increment, the incremental or reductive side of $w_{1}^{M V P}$, to let $r_{p, t}^{\prime}-r_{p, t}^{M V P}>0$. In other words, if the weight of first component asset of a portfolio on the efficient frontier (i.e., $w_{1}^{\prime}$ ) is on the incremental (respectively, reductive) side of $w_{1}^{M V P}$ to let $r_{p, t}^{\prime}-r_{p, t}^{M V P}>0$, then the weight range of first component asset of all portfolios on the efficient frontier is $w_{1} \geq w_{1}^{M V P}$ (respectively, $w_{1} \leq w_{1}^{M V P}$ ).

As to the procedure of this algorithm, it lists as follows. I first suppose that the efficient frontier locates on the incremental side of $w_{1}^{M V P}$, then the weight of first component asset of a portfolio on the efficient frontier is evaluated by $w_{1}^{\prime}=w_{1}^{M V P}+\Delta w_{1}$ and $\Delta w_{1}>0$. The return of a portfolio on the efficient frontier is obtained as $r_{p, t}^{\prime}=w_{1}^{\prime} \cdot r_{1, t}+\left(1-w_{1}^{\prime}\right) \cdot r_{2, t}$. If $r_{p, t}^{\prime}-r_{p, t}^{M V P}>0$, then $w_{1} \geq w_{1}^{M V P}$ or the efficient frontier locates on the incremental side of $w_{1}^{M V P}$. Conversely, if $r_{p, t}^{\prime}-r_{p, t}^{M V P}<0$, then the assumption of the efficient frontier locating on the incremental side of $w_{1}^{M V P}$ is incorrect. In this case, $w_{1} \leq w_{1}^{M V P}$ or the efficient frontier locates on the reductive side of $w_{1}^{M V P}$. Table 8 summarizes the results of constructing the efficient frontier by alternative developed capital allocation approaches and directional weight increment algorithm for the 21 bi-component asset portfolios. From Table 8, I find that, based on the assumption of the efficient frontier locating on the incremental side of $w_{1}^{M V P}$, the value of $r_{p, t}^{\prime}$ is greater than that of $r_{p}^{M V P}$ or $r_{p, t}^{\prime}-r_{p}^{M V P}>0$ for most of bi-component asset portfolios. The exceptions only are the WTI-GasNyh, WTI-Heating and SP500-DJ portfolios. These phenomena indicate that the weight range of first component asset of all portfolios on the efficient frontier is $w_{1} \geq w_{1}^{M V P}$ for most of bi-component asset portfolios except for the WTI-GasNyh, WTI-Heating and SP500-DJ portfolios. Regarding three exceptions: WTI-GasNyh, WTI-Heating and SP500-DJ portfolios, the weight range of first component asset of all portfolios on the efficient frontier is $w_{1} \leq w_{1}^{M V P}$. Subsequently, I take two examples via using the CWI approach, the GasNyh-DJ portfolio and WTI-GasNyh portfolio, to illustrate this algorithm where the GasNyh-DJ portfolio is the suitably effective bi-component portfolio selected in this study. For example, regarding the GasNyh-DJ portfolio, the value of $r_{p, t}^{\prime}(2.3274)$ is greater than that of $r_{p}^{M V P}$ (1.7164), indicating that the efficient frontier locates on the incremental side of $w_{1}^{M V P}$. Thus, the weight range of first component asset of all portfolios on the efficient frontier got from the CWI is $w_{1} \geq w_{1}^{M V P}=0.1094$. That is, the proportion of capital on the first component asset, the GasNyh, must be greater than $10.94 \%$ for GasNyh-DJ portfolio. On the contrary, regarding the WTI-GasNyh portfolio, the value of $r_{p, t}^{\prime}(2.6927)$ is less than that of $r_{p}^{M V P}$ (3.0981), indicating that the efficient frontier locates on the reductive side of $w_{1}^{M V P}$. Thus, the weight range of the first component asset of all portfolios on the efficient frontier got from the CWI is $w_{1} \leq w_{1}^{M V P}=0.6604$. In other words, the proportion of capital on the first component asset, the WTI must be less than $66.04 \%$ for WTI-GasNyh portfolio. The above results found from the proposed algorithm are consistent with those obtained from the CW approach for all 21 bi-component asset portfolios. 
Table 8. The messages of efficient frontier got from the directional weight increment algorithm and three developed capital allocation approaches.

\begin{tabular}{|c|c|c|c|c|c|c|c|c|}
\hline & $w_{1}^{M V P}$ & $r_{p}^{M V P}$ & $\sqrt{h_{p}^{M V P}}$ & $r_{p}^{\prime}$ & $w_{1}^{M V P}$ & $r_{p}^{M V P}$ & $\sqrt{h_{p}^{M V P}}$ & $r_{p}^{\prime}$ \\
\hline \multicolumn{5}{|c|}{ WTI-GasNyh $\left(w_{1} \leq w_{1}^{M V P}\right)$} & \multicolumn{4}{|c|}{ WTI-Heating $\left(w_{1} \leq w_{1}^{M V P}\right)$} \\
\hline MDWI & 0.6777 & 3.0630 & 1.9926 & $2.6575(<)$ & 0.4031 & 2.6148 & 1.9276 & $2.5461(<)$ \\
\hline DWI & 0.6724 & 3.0739 & 1.9926 & $2.6684(<)$ & 0.1973 & 2.6856 & 1.9084 & $2.6168(<)$ \\
\hline CWI & 0.6604 & 3.0981 & 1.9928 & $2.6927(<)$ & 0.3566 & 2.6308 & 1.9199 & $2.5621(<)$ \\
\hline \multicolumn{5}{|c|}{ GasNyh-Heating $\left(w_{1} \geq w_{1}^{M V P}\right)$} & \multicolumn{4}{|c|}{ SP500-DJ $\left(w_{1} \leq w_{1}^{M V P}\right)$} \\
\hline MDWI & 0.1975 & 3.0860 & 1.7790 & $3.4228(>)$ & -0.3597 & 1.4215 & 0.7313 & $1.3996(<)$ \\
\hline DWI & 0.2512 & 3.1764 & 1.7736 & $3.5132(>)$ & 0.2418 & 1.3556 & 0.7209 & $1.3337(<)$ \\
\hline CWI & 0.1946 & 3.0812 & 1.7796 & $3.4180(>)$ & -0.6261 & 1.4506 & 0.7424 & $1.4287(<)$ \\
\hline \multicolumn{5}{|c|}{ SP500-Nasdaq $\left(w_{1} \geq w_{1}^{M V P}\right)$} & \multicolumn{4}{|c|}{ DJ-Nasdaq $\left(w_{1} \geq w_{1}^{M V P}\right)$} \\
\hline MDWI & 1.1737 & 1.2942 & 0.6745 & $1.3190(>)$ & 1.2953 & 1.4511 & 0.7202 & $1.4978(>)$ \\
\hline DWI & 1.1469 & 1.2909 & 0.6743 & $1.3157(>)$ & 1.2136 & 1.4320 & 0.7191 & $1.4787(>)$ \\
\hline CWI & 1.1293 & 1.2887 & 0.6744 & $1.3135(>)$ & 1.2844 & 1.4485 & 0.7199 & 1.4953(>) \\
\hline \multicolumn{5}{|c|}{ WTI-SP500 $\left(w_{1} \geq w_{1}^{M V P}\right)$} & \multicolumn{4}{|c|}{ WTI-DJ $\left(w_{1} \geq w_{1}^{M V P}\right)$} \\
\hline MDWI & 0.1301 & 1.4206 & 0.7710 & $1.6480(>)$ & 0.1214 & 1.5069 & 0.7626 & $1.7125(>)$ \\
\hline DWI & 0.0109 & 1.2851 & 0.7290 & $1.5125(>)$ & -0.0010 & 1.3810 & 0.7187 & $1.5865(>)$ \\
\hline CWI & 0.1409 & 1.4329 & 0.7787 & $1.6604(>)$ & 0.1320 & 1.5178 & 0.7703 & $1.7233(>)$ \\
\hline \multicolumn{5}{|c|}{ WTI-Nasdaq $\left(w_{1} \geq w_{1}^{M V P}\right)$} & \multicolumn{4}{|c|}{ GasNyh-SP500 $\left(w_{1} \geq w_{1}^{M V P}\right)$} \\
\hline MDWI & 0.2092 & 1.4124 & 0.9554 & $1.6647(>)$ & 0.1127 & 1.6295 & 0.7311 & $2.2624(>)$ \\
\hline DWI & 0.0754 & 1.2436 & 0.9096 & $1.4959(>)$ & 0.0523 & 1.4382 & 0.7143 & $2.0711(>)$ \\
\hline CWI & 0.2106 & 1.4142 & 0.9564 & $1.6665(>)$ & 0.1153 & 1.6376 & 0.7326 & $2.2705(>)$ \\
\hline \multicolumn{5}{|c|}{ GasNyh-DJ $\left(w_{1} \geq w_{1}^{M V P}\right)$} & \multicolumn{4}{|c|}{ GasNyh-Nasdaq $\left(w_{1} \geq w_{1}^{M V P}\right)$} \\
\hline MDWI & 0.1065 & 1.7077 & 0.7229 & $2.3188(>)$ & 0.1739 & 1.7207 & 0.9043 & $2.3784(>)$ \\
\hline DWI & 0.0464 & 1.5241 & 0.7062 & $2.1351(>)$ & 0.0989 & 1.4740 & 0.8821 & $2.1317(>)$ \\
\hline CWI & 0.1094 & 1.7164 & 0.7244 & $2.3274(>)$ & 0.1696 & 1.7065 & 0.9018 & $2.3642(>)$ \\
\hline \multicolumn{5}{|c|}{ Heating-SP500 $\left(w_{1} \geq w_{1}^{M V P}\right)$} & \multicolumn{4}{|c|}{ Heating-DJ $\left(w_{1} \geq w_{1}^{M V P}\right)$} \\
\hline MDWI & 0.1685 & 1.5222 & 0.7496 & $1.8183(>)$ & 0.1545 & 1.5940 & 0.7378 & $1.8683(>)$ \\
\hline DWI & 0.0644 & 1.3681 & 0.7214 & $1.6643(>)$ & 0.0572 & 1.4606 & 0.7130 & $1.7349(>)$ \\
\hline CWI & 0.1735 & 1.5297 & 0.7523 & $1.8258(>)$ & 0.1617 & 1.6039 & 0.7415 & $1.8781(>)$ \\
\hline \multicolumn{5}{|c|}{ Heating-Nasdaq $\left(w_{1} \geq w_{1}^{M V P}\right)$} & \multicolumn{4}{|c|}{ WTI-UDI $\left(w_{1} \geq w_{1}^{M V P}\right)$} \\
\hline MDWI & 0.2470 & 1.5449 & 0.9147 & $1.8659(>)$ & 0.0875 & -0.0481 & 0.4284 & $0.4906(>)$ \\
\hline DWI & 0.1356 & 1.3661 & 0.8858 & $1.6871(>)$ & 0.1050 & -0.0010 & 0.4263 & $0.5377(>)$ \\
\hline CWI & 0.2464 & 1.5440 & 0.9144 & $1.8649(>)$ & 0.0782 & -0.0732 & 0.4312 & $0.4654(>)$ \\
\hline \multicolumn{5}{|c|}{ GasNyh-UDI $\left(w_{1} \geq w_{1}^{M V P}\right)$} & \multicolumn{4}{|c|}{ Heating-UDI $\left(w_{1} \geq w_{1}^{M V P}\right)$} \\
\hline MDWI & 0.0626 & 0.0117 & 0.4559 & $0.9559(>)$ & 0.0865 & -0.0212 & 0.4363 & $0.5862(>)$ \\
\hline DWI & 0.0718 & 0.0549 & 0.4552 & $0.9991(>)$ & 0.1092 & 0.0477 & 0.4335 & $0.6552(>)$ \\
\hline CWI & 0.0522 & -0.0373 & 0.4583 & $0.9068(>)$ & 0.0779 & -0.0472 & 0.4387 & $0.5602(>)$ \\
\hline \multicolumn{5}{|c|}{ SP500-UDI $\left(w_{1} \geq w_{1}^{M V P}\right)$} & \multicolumn{4}{|c|}{ DJ-UDI $\left(w_{1} \geq w_{1}^{M V P}\right)$} \\
\hline MDWI & 0.1969 & 0.0225 & 0.4459 & $0.3338(>)$ & 0.2090 & 0.0642 & 0.4405 & $0.3974(>)$ \\
\hline DWI & 0.2965 & 0.1776 & 0.4383 & $0.4889(>)$ & 0.3069 & 0.2273 & 0.4332 & $0.5605(>)$ \\
\hline CWI & 0.1592 & -0.0361 & 0.4526 & $0.2751(>)$ & 0.1705 & 0.0000 & 0.4473 & $0.3333(>)$ \\
\hline \multicolumn{9}{|c|}{ Nasdaq-UDI $\left(w_{1} \geq w_{1}^{M V P}\right)$} \\
\hline MDWI & 0.1443 & -0.0773 & 0.4644 & $0.2091(>)$ & & & & \\
\hline DWI & 0.1999 & 0.0022 & 0.4611 & $0.2888(>)$ & & & & \\
\hline CWI & 0.1205 & -0.1113 & 0.4678 & $0.1751(>)$ & & & & \\
\hline
\end{tabular}

Note: (1) The numbers in columns ' $w_{1}^{M V P}$ ', ' $r_{p}^{M V P}$ ' and ' $\sqrt{h_{p}^{M V P}}$ ' are summarized from Table 6. (2) $r_{p}^{\prime}$ and $\sqrt{h_{p}^{\prime}}$ respectively denote the return and volatility of portfolio on the efficient frontier based on the assumption of the efficient frontier locating on the incremental side of $w_{1}^{M V P}$. In other words, $r_{p, t}^{\prime}=w_{1}^{\prime} \cdot r_{1, t}+\left(1-w_{1}^{\prime}\right) \cdot r_{2, t}, h_{p, t}^{\prime}=\left(w_{1}^{\prime}\right)^{2} \cdot h_{11, t}+$ $\left(w_{2}^{\prime}\right)^{2} \cdot h_{22, t}+2 w_{1}^{\prime} \cdot w_{2}^{\prime} \cdot h_{12, t}=\left(w_{1}^{\prime}\right)^{2} \cdot h_{11, t}+\left(1-w_{1}^{\prime}\right)^{2} \cdot h_{22, t}+2 w_{1}^{\prime} \cdot\left(1-w_{1}^{\prime}\right) \cdot h_{12, t}$ where $w_{1}^{\prime}=w_{1}^{M V P}+\Delta w_{1}$ and $\Delta w_{1}>0$. (3) The inequality expression inside the bracket beside the panel name of bi-component portfolio denotes the weight range of first component asset of portfolios on the efficient frontier for that bi-component portfolio. (4) Regarding the rows 'MDWI', 'DWI' and 'CWI', the symbol $>$ (respectively, $<$ ) in the bracket beside the numbers in column ' $r$ ', denotes the value of return of a portfolio at the efficient frontier $\left(r_{p}^{\prime}\right)$ is greater (respectively, lower) than the value of return of MVP $\left(r_{p}^{M V P}\right)$ obtained by the MDWI, DWI and CWI approaches. 


\section{Conclusions}

In this study, a positive definite and diagonal BEKK type of bivariate GARCH $(1,1)$ model was used to estimate the conditional variance and covariance of 21 bi-component asset portfolios. I constructed the 21 bi-component asset portfolios via using alternative two of the seven assets dispersed among the oil, stock, and FX markets in the US. Subsequently, for each of 21 bi-component asset portfolios, this study used one traditional asset allocation approach and its improvement methods to find all the messages of the MVP and the weight range of component assets of all portfolios on the efficient frontier, and further explored the following issues. The improvement methods included the three developed capital allocation approaches and a directional weight increment algorithm. First, among the seven assets, how can one pick two assets to construct the suitably effective bi-component portfolio? Subsequently, how can one distribute the capital into the selected two assets? Second, which capital allocation approach has the best forecasting performance among three developed capital allocation approaches that can find the weight combination of the MVP quickly and precisely? Third, is the weight range of component assets of all portfolios on the efficient frontier from the proposed directional weight increment algorithm consistent with that obtained from the traditional asset allocation approach?

The empirical findings can be summarized as follows. First, as shown in the preliminary data analysis, the assets in the oil market incur the highest risk, followed by those in the stock market, whereas the UDI incurs the lowest risk among three markets in the US. Moreover, the price trend between the UDI and the assets in the oil market has a significant opposite direction, and this phenomenon is consistent with that found from the conditional correlation between them. Second, three stock market portfolios have the greatest value of positive correlation coefficients, followed by three oil market portfolios and nine mixed oil-stock market portfolios, whereas three mixed oil-FX market portfolios and three mixed stock-FX market portfolios have the smallest and negative value of correlation coefficients. Third, the oil (respectively, the mixed oil-FX and the mixed stock-FX) market portfolios have the largest (respectively, smallest) value of return and the highest (respectively, lowest) level of risk. In addition, the stock market portfolios and the mixed oil-stock market portfolios have an intermediate value of return and a middle level of risk. However, both the mixed oil-FX market portfolios and the mixed stock-FX market portfolios are the relative minimum-variance portfolios based on the volatility risk measure, whereas the above two market types of portfolios are also the relatively most inefficient portfolios based on the CV risk measure. The contradictory results appear in the portfolio picking process for two different types of risk measure. Hence, this study proposes an asset selection criterion, based on the values of the difference and the sum of two different rank-order numbers respectively corresponding to the volatility and CV risk measures, to select the suitably effective portfolio for two types of investors. Two types of investors are willing and not willing to bear risk. The SP500-Nasdaq $\left(w_{1} \geq w_{1}^{M V P}=1.1293\right)$ and GasNyh-DJ ( $\left.w_{1} \geq w_{1}^{M V P}=0.1094\right)$ portfolios are selected. Notably, the inequality expression inside the bracket beside the above bi-components asset portfolios denotes the weight range of the first component asset of all portfolios on the efficient frontier found from both the CWI approach and the directional weight increment algorithm. Moreover, the SP500-Nasdaq and GasNyh-DJ portfolios respectively belong to the stock market portfolios and the mixed oil-stock market portfolios, which are the relatively most efficient portfolios. Fourth, this study regards the MVP obtained through the CW approach as the benchmark, and then evaluates the forecast performance for the three developed capital allocation approaches by using the portfolio efficiency criterion based on two different types of risk measure. I find that the capital allocation approaches using the entire sample weight forecasts, the MDWI and CWI, have the best forecast performance, whereas the capital allocation approach using the last observation sample weight forecast, the DWI, has the worst forecast performance. Notably, the MVP is the start point of the efficient frontier, and the three capital allocation approaches can find all the messages of MVP for each bi-component asset portfolios quickly and precisely. Finally, this study uses the features of the efficient frontier to propose a directional weight increment algorithm to find rapidly and accurately the weight range of 
the component assets of all portfolios on the efficient frontier. The results found from the proposed algorithm are consistent with those obtained from a traditional approach, the CW.

Based on the above empirical results, I propose the following important policy implications for investors and fund managers. First, the UDI is a good hedge asset, especially for assets in the oil market, since the portfolios including the UDI have the smallest and even negative value of correlation coefficients, and the above portfolios thus have a lower risk according to portfolio theory. Second, regarding two types of investors who are willing and not willing to bear risk, the fund managers should use the proposed asset selection criterion to select the suitable assets in the financial market to construct an effective portfolio. The asset selection criterion uses the values of volatility and CV on the MVPs of all possible component-based portfolios to choose the assets because the MVP is the start point of the efficient frontier of component-based portfolios. Moreover, the asset selection criterion is a compromise method in the portfolio picking process because it can solve the contradictory results appearing in the portfolios selection process under two different risk measures, the volatility and CV. Third, to identify the efficient frontier efficiently, investors should use the capital allocation approaches using the entire sample weight forecasts, the MDWI and CWI, to find the weight combination of MVP quickly and precisely, and then they can utilize a directional weight increment algorithm to find the weight range of component assets of all portfolios on the efficient frontier rapidly.

Funding: This research received no external funding.

Conflicts of Interest: The author declares no conflict of interest.

\section{References}

1. Markowitz, H.M. Portfolio selection. J. Financ. 1952, 7, 77-91.

2. Tasca, P.; Mavrodiev, P.; Schweitzer, F. Quantifying the impact of leveraging and diversification on systemic risk. J. Financ. Stab. 2014, 15, 43-52.

3. Managing Investments for Sustainable Returns. Available online: https://www.calpers.ca.gov/page/ investments/sustainable-investments-program/esg-integration/managing-investments-sustainablereturns (accessed on 29 June 2020).

4. Yang, T.; Liu, J.; Ying, Q.; Yousaf, T. Media Coverage and Sustainable Stock Returns: Evidence from China. Sustainability 2019, 11, 2335.

5. Lin, S.L.; Lu, J.; Su, J.B.; Chen, W.P. Sustainable Returns: The Effect of Regional Industrial Development Policy on Institutional Investors' Behavior in China. Sustainability 2018, 10, 2769.

6. Bailey, W.; Stulz, R.M. Benefits of international diversification: The case of pacific basin stock markets. J. Portf. Manag. 1990, 16, 57-61.

7. Brinson, G.P.; Singer, B.D.; Beebower, G.L. Determinants of portfolio performance II: An update. Financ. Anal. J. 1991, 47, 40-48.

8. Chen, H.C.; Ho, K.Y.; Lu, C.; Wu, C.H. Real estate investment trusts: An asset allocation perspective. J. Portf. Manag. 2005, 31, 46-54.

9. Gruble, H. Internationally diversified portfolios: Welfare gains and capital flows. Am. Econ. Rev. 1968, $58,1299-1314$.

10. Jorion, P. Asset allocation with hedged and un-hedged foreign stocks and bonds. J. Portf. Manag. 1989, 15, 49-54.

11. Levy, H.; Lerman, Z. The benefits of international diversification in bonds. Financ. Anal. J. 1988, 44, 56-64.

12. Levy, H.; Sarnat, M. International diversification of investment portfolios. Am. Econ. Rev. 1970, 17, 668-675.

13. Solnik, B. Why not diversify internationally rather than domestically? Financ. Anal. J. 1974, 30, 48-54.

14. Bae, G.I.; Kim, W.C.; Mulvey, J.M. Dynamic asset allocation for varied financial markets under regime switching framework. Eur. J. Oper. Res. 2014, 234, 450-458.

15. Chalmers, J.; Kaul, A.; Phillips, B. The wisdom of crowds: Mutual fund investors' aggregate asset allocation decisions. J. Bank. Financ. 2013, 37, 3318-3333.

16. He, L.; Liang, Z. Optimal dynamic asset allocation strategy for ELA scheme of DC pension plan during the distribution phase. Insur. Math. Econ. 2013, 52, 404-410. 
17. Lioui, A. Time consistent vs. time inconsistent dynamic asset allocation: Some utility cost calculations for mean variance preferences. J. Econ. Dyn. Control 2013, 37, 1066-1096.

18. Shen, Y.; Siu, T.K. Asset allocation under stochastic interest rate with regime switching. Econ. Model. 2012, 29, 1126-1136.

19. Platanakis, E.; Sutcliffe, C.; Ye, X. Horses for Courses: Mean-Variance for Asset Allocation and $1 / \mathrm{N}$ for Stock Selection. Eur. J. Oper. Res. 2020. [CrossRef]

20. Shimizu, H.; Shiohama, H. Constructing inverse factor volatility portfolios: A risk-based asset allocation for factor investing. Int. Rev. Financ. Anal. 2020, 68, 101438.

21. Aziz, N.S.A.; Vrontos, S.; Hasim, H.M. Evaluation of multivariate GARCH models in an optimal asset allocation framework. North Am. J. Econ. Financ. 2019, 47, 568-596.

22. Cheang, C.W.; Olmo, J.; Ma, T.; Sung, M.C.; McGroarty, F. Optimal asset allocation using a combination of implied and historical information. Int. Rev. Financ. Anal. 2000, 67, 101419.

23. Lv, F.; Yang, C.; Fang, L. Do the crude oil futures of the Shanghai International Energy Exchange improve asset allocation of Chinese petrochemicalrelated stocks? Int. Rev. Financ. Anal. 2020. [CrossRef]

24. Caporin, M.; McAleer, M. Do we really need both BEKK and DCC? A tale of two multivariate GARCH models. J. Econ. Surv. 2012, 26, 736-751.

25. Baba, Y.; Engle, R.F.; Kraft, D.K.; Kroner, K. Multivariate Simultaneous Generalized ARCH; University of California: Oakland, CA, USA, 1990.

26. Su, J.B. The interrelation of stock markets in China, Taiwan and Hong Kong and their constructional portfolio's value-at-risk estimate. J. Risk Model Valid. 2014, 8, 69-127.

27. Engle, R.F.; Kroner, K.F. Multivariate simultaneous GARCH. Econom. Theory 1995, 11, 122-150.

28. Moschini, G.C.; Myers, R.J. Testing for constant hedge ratios in commodity markets: A multivariate GARCH approach. J. Empir. Financ. 2002, 9, 589-603.

29. Su, J.B. How the Quantitative Easing Affect the Spillover Effects between the Metal Market and United States Dollar Index? J. Rev. Glob. Econ. 2016, 5, 254-272.

30. Su, J.B. Volatility forecasts of alternative bivariate GARCH models: Evidence from the stock markets in Asia. J. Financ. Studies 2017, 25, 43-83.

31. Su, J.B.; Hung, J.C. The Value-at-Risk estimate of stock and currency-stock portfolios' returns. Risks 2018, $6,133$.

32. Markowitz, H.M. Portfolio Selection: Efficient Diversification of Investments; John Wiley \& Sons: New York, NY, USA, 1959.

33. Jarque, C.M.; Bera, A.K. A test for normality of observations and regression residuals. Int. Stat. Rev. 1987, 55, 163-172.

(C) 2020 by the author. Licensee MDPI, Basel, Switzerland. This article is an open access article distributed under the terms and conditions of the Creative Commons Attribution (CC BY) license (http://creativecommons.org/licenses/by/4.0/). 